\title{
Interferon in relapsing-remitting multiple sclerosis (Review)
}

Rice GPA, Incorvaia B, Munari LM, Ebers G, Polman C, D'Amico R, Parmelli E, Filippini G

Rice GPA, Incorvaia B, Munari LM, Ebers G, Polman C, D'Amico R, Parmelli E, Filippini G.

Interferon in relapsing-remitting multiple sclerosis.

Cochrane Database of Systematic Reviews 2001, Issue 4. Art. No.: CD002002.

DOI: 10.1002/14651858.CD002002.

www.cochranelibrary.com 
TABLE OF CONTENTS

HEADER 1

ABSTRACT

PLAIN LANGUAGE SUMMARY

BACKGROUND

OBJECTIVES

METHODS

RESULTS

DISCUSSION

AUTHORS' CONCLUSIONS

ACKNOWLEDGEMENTS

REFERENCES

CHARACTERISTICS OF STUDIES

DATA AND ANALYSES

Analysis 1.1. Comparison 1 interferon versus placebo: primary outcomes, Outcome 1 Patients with at least one exacerbation until $1 \mathrm{yr}$.

Analysis 1.2. Comparison 1 interferon versus placebo: primary outcomes, Outcome 2 Patients with at least one exacerbation until 1 year: subgroup analysis.

Analysis 1.3. Comparison 1 interferon versus placebo: primary outcomes, Outcome 3 Patients with at least one exacerbation at 2 yrs.

Analysis 1.4. Comparison 1 interferon versus placebo: primary outcomes, Outcome 4 Patients with at least one exacerbation at 2 yrs (best scenario).

Analysis 1.5. Comparison 1 interferon versus placebo: primary outcomes, Outcome 5 Patients with at least one exacerbation at 2 yrs (worst scenario).

Analysis 1.6. Comparison 1 interferon versus placebo: primary outcomes, Outcome 6 Patients who progressed at 2 yrs. .......... Analysis 1.7. Comparison 1 interferon versus placebo: primary outcomes, Outcome 7 Patients who progressed at 2 yrs (best scenario).

Analysis 1.8. Comparison 1 interferon versus placebo: primary outcomes, Outcome 8 Patients who progressed at 2 yrs (worst scenario).

Analysis 1.9. Comparison 1 interferon versus placebo: primary outcomes, Outcome 9 Mean change in disability (EDSS) at 2 yrs.

Analysis 2.1. Comparison 2 Interferon versus placebo: secondary outcomes, Outcome 1 Patients who required steroid treatment until first year.

Analysis 2.2. Comparison 2 Interferon versus placebo: secondary outcomes, Outcome 2 Patients who required steroid treatment until 2 years.

Analysis 2.3. Comparison 2 Interferon versus placebo: secondary outcomes, Outcome 3 Patients with at least one hospital admission until 2 years.

Analysis 3.1. Comparison 3 interferon versus placebo: adverse events, Outcome 1 Patients who had clinical adverse events during treatment.

Analysis 3.2. Comparison 3 interferon versus placebo: adverse events, Outcome 2 Patients who had abnormal laboratory values during treatment.

ADDITIONAL TABLES

APPENDICES

WHAT'S NEW

HISTORY

CONTRIBUTIONS OF AUTHORS

DECLARATIONS OF INTEREST

SOURCES OF SUPPORT

INDEX TERMS 
[Intervention Review]

\section{Interferon in relapsing-remitting multiple sclerosis}

George PA Rice¹, Barbara Incorvaia², Luca M. Munari³, George Ebers ${ }^{4}$, Chris Polman 5 , Roberto D'Amico ${ }^{6}$, Elena Parmelli6, Graziella Filippini 7

${ }^{1}$ Clinical Neurological Sciences, University of Western Ontario, London, Canada. ${ }^{2}$ Cochrane Neurological Network, Osservatorio Epidemiologico - Regione Umbria, Perugia, Italy. ${ }^{3}$ Azienda Ospedaliera Ospedale Niguarda Ca' Granda, Milan, Italy. ${ }^{4} \mathrm{Clinical}$ Neurology, University of Oxford, Oxford, UK. ${ }^{5}$ Neurology, VU Medical Centre, Amsterdam, Netherlands. ${ }^{6}$ Department of Oncology and Hematology, University of Modena and Reggio Emilia, Modena, Italy. ${ }^{7}$ Neuroepidemiology Unit, Fondazione I.R.C.C.S. - Istituto Neurologico C.Besta, Milano, Italy

Contact address: Graziella Filippini, Neuroepidemiology Unit, Fondazione I.R.C.C.S. - Istituto Neurologico C.Besta, via Celoria 11, Milano, 20133, Italy.gfilippini@istituto-besta.it.

Editorial group: Cochrane Multiple Sclerosis and Rare Diseases of the CNS Group

Publication status and date: Edited (no change to conclusions), published in Issue 1, 2010.

Citation: Rice GPA, Incorvaia B, Munari LM, Ebers G, Polman C, D'Amico R, Parmelli E, Filippini G. Interferon in relapsing-remitting multiple sclerosis. Cochrane Database of Systematic Reviews 2001, Issue 4. Art. No.: CD002002. DOI: 10.1002/14651858.CD002002.

Copyright () 2010 The Cochrane Collaboration. Published by John Wiley \& Sons, Ltd.

\section{A B S T R A C T}

\section{Background}

Recombinant interferons have been shown to suppress both the clinical and magnetic resonance imaging (MRI) measures of disease activity in patients with relapsing remitting multiple sclerosis (RRMS).

\section{Objectives}

The objective of this review was to assess the effects of recombinant interferons in adults with RRMS.

\section{Search methods}

We searched the Cochrane Multiple Sclerosis Group trials register (April 2007), MEDLINE (January 1966 April 2007), EMBASE (January 1985 to April 2007) and reference lists of articles. We also contacted manufacturers and researchers in the field

\section{Selection criteria}

The trials selected were double-blind, placebo-controlled, randomised trials of RRMS patients who were treated with recombinant interferon, given by the subcutaneous or the intramuscular route.

\section{Data collection and analysis}

All reviewers independently assessed trial quality and extracted data. Study authors were contacted for additional information. Adverse effects information was collected from the trials.

\section{Main results}

Although eight trials involving 1301 participants were included in this review, only 919 (71\%) contributed to the results concerning exacerbations and progression of the disease at two years. Specifically interferon significantly reduced the occurrence of exacerbations (Relative risk [RR] 0.80, 95\% confidence interval [Cl] 0.73 to $0.88, \mathrm{p}<0.001)$ and progression of the disease $(\mathrm{RR} 0.69,95 \% \mathrm{Cl} 0.55$ to $0.87, \mathrm{p}$ $=0.002$ ) two years after randomisation. However, the correct assignment of dropouts was essential to the demonstration of efficacy, most conspicuously concerning the effect of the drug on disease progression. If interferon-treated participants who dropped out were deemed to have progressed (worst case scenario) the significance of these effects was lost (RR $1.31,95 \% \mathrm{Cl} 0.60$ to 2.89 , $\mathrm{p}=0.5$ ). The evolution in magnetic resonance imaging (MRI) technology in the decade in which these trials were performed and different reporting of data among 
trials made it impossible to perform a quantitative analysis of the MRI results. Both clinical and laboratory side effects reported in the trials were more frequent in treated participants than in controls; there was no information after two years of follow-up. The impact of interferon treatment (and its side effects) on the quality of life of patients was not reported in any trial included in this review.

\section{Authors' conclusions}

The efficacy of interferon on exacerbations and disease progression in patients with relapsing remitting MS was modest after one and two years of treatment. Interferon administered by the oral route was not effective for prevention of relapses. Longer follow-up and more uniform reporting of clinical and MRI outcomes among these trials might have allowed for a more convincing conclusion.

\section{PLAIN LANGUAGE SUMMARY}

\section{The use of interferons for treating people with the relapsing-remitting form of multiple sclerosis}

Multiple sclerosis (MS) is a chronic disease of the nervous system which affects young and middle-aged adults. Repeated damage to the myelin sheaths and other parts of the nerves can lead to serious disability. MS may be related to the immune system. Interferons have several effects on the immune system, and act against viruses. Interferons can help to reduce disability and attacks for people with multiple sclerosis, but there is not enough evidence about their usefulness in the long term. The review of trials found that interferons administered intramuscularly or subcutaneously can lead to a moderate reduction in recurrences and disability in people who have MS with remissions. Interferon-1a administered by the oral route was not effective for prevention of relapses. Side effects were usually influenza-like symptoms, injection site-reactions, pains in the joints and muscles, fatigue and headache. 


\section{B A C K G R O U N D}

\section{Description of the condition}

Multiple sclerosis (MS) is the commonest seriously disabling disease of young adults. Although the etiology is largely unknown, it is believed that MS develops in genetically predisposed individuals and that autoimmune mechanisms play a central role in its pathogenesis (Noseworthy 1999). Environmental factors are suspected to play a role, but the magnitude of their effect has not been clearly elucidated.

\section{Description of the intervention}

Interferons have been studied extensively in MS for more than 20 years, reflecting both the desperate need for an effective treatment for MS and the desire to expand the role for interferons, which had been found helpful only in some malignancies and viral hepatitis. It could be conceded that the development of interferon in recent years was largely fuelled by the success of the drug in a few early pilot trials (Jacobs 1981; Knobler 1984a).

\section{How the intervention might work}

Interferons have many actions of potential relevance to MS Antiviral effects, pleiotropic effects on the immune system and blood brain barrier could all contribute to a benefit in patients with MS (Hohlfeld 1997). It is not known which of these mechanisms underlies the reported efficacy of interferons in the disease. Although tantalizing immunological effects of interferons in MS have been reported (induction of interleukin-6,10), readers should be reminded that these observations are established only for certain populations of treated patients, compared to controls. No single biochemical marker has been linked to a clinical or magnetic resonance imaging (MRI) response in individual patients, although research in this area is promising (vanBoxel-Dezaire2000).

\section{Why it is important to do this review}

Recombinant interferons have been approved by the regulatory authorities of many countries for the treatment of relapsing remitting MS (RRMS) but many questions remain concerning their efficacy in preventing progression of the disease and increased disability in the long term, the optimum dose and duration of treatment and the consequences of discontinuation of the drug. No systematic reviews of this subject are known to exist.

\section{OB JECTIVES}

The efficacy and safety of recombinant interferons in the treatment of patients with relapsing remitting MS (RRMS) were evaluated. The primary questions were whether recombinant interferon was more effective than placebo in decreasing the number of patients who experience clinical relapses and disease progression.

The secondary objectives were:

(1) To examine the efficacy of recombinant interferon in reducing the need for corticosteroid treatment and hospitalisation of RRMS patients;

(2) To evaluate the incidence and seriousness of side effects and adverse events;

(3) To assess the effect of interferon on magnetic resonance imaging (MRI) which is a surrogate outcome.

\section{METHODS}

\section{Criteria for considering studies for this review}

\section{Types of studies}

We included only randomised, double blind, placebo-controlled trials of recombinant interferons. Uncontrolled and nonrandomised trials were excluded. We excluded trials which were confounded by other treatments such as immunosuppressive drugs. Trials which addressed the efficacy of interferons in progressive forms of MS will be reviewed at a later date.

\section{Types of participants}

The diagnosis of multiple sclerosis was accepted on the basis of established clinical and paraclinical evidence. The definition of Poser was most commonly applied (Poser 1983). Patients in a relapsing-remitting phase were included. This is defined as the phase of the disease characterised by one or more exacerbations followed by complete or partial recovery. Patients are clinically stable between exacerbations.

\section{Types of interventions}

We considered all trials in which alfa- or beta- recombinant interferons had been compared to placebo. Trials were not excluded on the basis of dose, duration of treatment, route of administration or length of follow up. For trials in which treatment effects were reported for more than one dose, we restricted the analysis to the higher dose (which is the dose most frequently used in clinical practice).

\section{Types of outcome measures}

\section{Primary outcomes}

The primary outcome measures included:

(1) the number of patients who continued to experience exacerbations during the scheduled treatment period and the follow-up period. Exacerbation was defined as newly developed or recently worsened symptoms of neurologic dysfunction that lasted more than 24 hours, with or without objective confirmation, and that stabilised or resolved either partially or completely;

(2) the number of patients who progressed during the first two years of treatment. The definition of progression was taken from the original articles. Most studies used the Expanded Disability Status Scale (EDSS) (Kurtzke 1983) and the definition of progression was a sustained (three or six months) increase in EDSS of at least one point recorded out of exacerbation. EDSS is the most widely used disability measure in clinical trials of MS. It is based on the results of a neurologic examination and the patient's ability to walk. Scores range from 0 (no neurologic abnormality) to 10 (death from MS) (Table 1);

(3) mean change in disability score (EDSS) in treatment groups at the end of the follow-up period;

(4) the number of patients who were unable to walk without aid (EDSS greater than 5.5) at the end of the follow-up period.

\section{Secondary outcomes}

The secondary outcome measures included:

(1) time to first exacerbation;

(2) time to progression in disability; 
(3) the number of patients who underwent steroid administration during interferon treatment and follow-up;

(4) the number of patients who were hospitalised during treatment and follow-up;

(5) the number of patients experiencing side effects or adverse events;

(6) the effect of treatment on the magnetic resonance imaging which is considered a surrogate outcome. It included:

(a) the mean change of total lesion load on T2-weighted images during treatment and follow-up;

(b) the number of patients who continued to show gadoliniumenhancing lesions during treatment and follow-up. Gadolinium is a paramagnetic contrast agent for magnetic resonance that identifies deficiencies in the blood brain barrier.

\section{Search methods for identification of studies}

A systematic search without language resctrictions was conducted to identify all relevant publisched and unpublished randomised controlled trials. We identified 125 articles in MEDLINE, a further 23 in EMBASE, 46 by handsearching and 14 in the Cochrane Controlled Trials Register. We did not identify any unpublished trials.

\section{Electronic searches}

We searched the following databases:

1. Cochrane Multiple Sclerosis Group trials register (April 2007)

2. MEDLINE January 1966 to April 2007 (Appendix 1)

3. EMBASE January 1988 to April 2007 (Appendix 2)

\section{Searching other resources}

4. Handsearching of the references quoted in the identified trials, symposia reports (1990 to 2007) from the most important neurological associations and MS Societies in Europe and America; 5. contact with researchers who were participating in trials on interferons; and

6. contact with the following companies in order to identify unpublished trials or data missing from articles: Biogen (Avonex: interferon beta-1a), Ares Serono International SA (Rebif: interferon beta-1a), Schering AG (Betaseron or Betaferon: interferon beta-1b), Berlex Laboratories (Betaseron or Betaferon: interferon beta-1b), Roche (Roferon: interferon alfa- 2a).

\section{Data collection and analysis}

\section{STUDY SELECTION}

The reviewers independently scrutinised the trials and decided which trials met the inclusion criteria. We resolved all disagreement about including or excluding a trial by discussion among the reviewers.

\section{QUALITY ASSESSMENT}

The trials were judged on the reported method of allocation concealment as: adequate (A), unclear (B) or inadequate (C) as outlined in the "Cochrane Reviewers' Handbook " (Clarke 2000). The assessment also included the adequacy of blinding, the definition and clinical relevance of outcomes, the number of participants who withdrew or were withdrawn from the trial after randomisation and the number with incomplete follow-up. We also addressed whether an intention-to treat analysis was done or could be done. When this information was not reported, we submitted a formal request to the trial sponsors. When investigators did not respond, the item was considered unclear.
We extracted data concerning side effects or adverse events for each effect or event whenever possible. For trials in which they were reported for more than one dose, we reported the data pertaining to the higher dose.

\section{DATA EXTRACTION}

The reviewers extracted the data independently: characteristics of participants, interventions (type of interferon, type of placebo, dose, duration of treatment, length of follow-up), outcome measures, use of corticosteroids and need for hospitalisation during the scheduled treatment and follow up, side effects and adverse events. We also extracted the date and location of trial, sponsor of trial (specified, known or unknown) and publication status. Disagreement about quality assessment and data were resolved by discussion among the reviewers. All data were registered on a collection form.

\section{DATA ANALYSIS}

We sought data on the number of participants in the treatment groups and with each outcome, irrespective of compliance or completeness of follow-up, in the articles or requested from the authors in order to do an "intention-to-treat" analysis.

We analysed binary outcomes by calculating relative risks for each trial with the uncertainty in each trial being expressed using 95\% confidence intervals ( $\mathrm{Cl}$ ). We analysed continuous outcomes according to the difference between their means. For each outcome we calculated a weighted treatment effect across trials. We expressed results as a weighted estimate of relative risk with the relative $95 \% \mathrm{Cl}$ for binary outcomes, and difference between means across trials for continuous outcomes. We performed statistical analyses with the Review Manager software developed by the Cochrane Collaboration (4.1).

We considered the number of participants who need to be treated (NNT) to prevent one event for the following outcomes:

- participants who continued to experience exacerbations during the first year;

- participants who continued to experience exacerbations during the first two years;

- participants who progressed during the first two years.

The NNT has been calculated as the reciprocal of the absolute risk reduction (1/ARR). ARR is the risk difference between participants treated with interferon and controls. It is known that ARR is sensitive to factors that change the baseline risk such as the outcome considered, participants' characteristics and the clinical setting (Smeeth 1999). Since the baseline risk often varies appreciably between the trials, we calculated ARR according to different levels of baseline risk (BR), ranging from 0.1 to 0.9 , as follows: $A R R=B R-(R R \times B R)$, where $R R$ is the relative risk resulting from meta analysis.

Homogeneity among trial results was evaluated using a standard chi squared test and we rejected the hypothesis of homogeneity if the $p$ value was less than 0.10 . Trial outcomes were combined using a fixed effect approach (Yusuf 1985) unless there was a significant heterogeneity, in which case we summarised results using a random effects model (DerSimonian 1986c).

We did subgroup analyses because we hypothesised a priori that responses might differ according to: (1) type of interferon; (2) dose; (3) duration of treatment; and (4) length of follow-up. 
We evaluated heterogeneity in the effect of treatment between studies by meta-regression in order to analyse associations between treatment effect and study characteristics. Metaregression was done in STATA.

We conducted a sensitivity analysis to address the effect of withdrawn and lost to follow-up on the major outcomes. The best case scenario (with regards to treatment) assumed that none of the patients who were excluded from the analysis in the interferontreated group had the outcome of interest, while all those excluded from the control group did and vice versa for the worst case scenario.

\section{RES U L T S}

\section{Description of studies}

For the first version of this review 208 articles identified by the search strategy, eighteen articles were selected provisionally, on the basis of the inclusion criteria mentioned above.

We excluded eleven studies after reading the full published papers: two studies were open-label (Rudick 1998; Herndon 1999); in three studies participants were treated with natural interferon-alfa (IFNalfa) (Knobler 1984; AUSTIMS 1989; Milanese 1990); in one study only immunological, not clinical, outcomes were reported (Hirsch 1986); one study was a dose-comparison trial of interferon beta-1a without a placebo group (Pozzilli 1997); one study was performed on progressive MS participants and included only two participants with relapsing-remitting MS (Rudge 1995); one study reported data only relating to the placebo group of a RCT on interferon beta-1a (IFNB-1a) (Simon 1999) and in one study (Jacobs 2000) participants were treated after a first exacerbation, prior to a definite diagnosis of MS. Finally, one study was excluded because neither blinding criteria nor clinical outcomes were clearly described (Schwartz 1997). (See table of excluded studies).

During the update of the review we first identified two studies that met the inclusion criteria. One of them (Granger 2003) was excluded because it is a secondary analysis of a study already included in this review (The MSCRG 1996) using FIM instrument instead of EDSS to assess disease progression.

Thus eight trials contributed to this review: the earliest was published in 1993 and the most recent in 2003 (Knobler 1993; IFNB MS Group 1993; Durelli 1994; The MSCRG 1996; The PRISMS 1998; Myhr 1999; The OWIMS 1999; Polman 2003). A total of 1301 experimental participants (in the higher dose arms which were compared with placebo treated participants), including 658 treated with interferon and 643 randomised to placebo, were included in this review. One multicenter study of subcutaneous IFNB-1a (The PRISMS 1998) accounted for 371 (30.5\%) participants while a study of intramuscular IFNA-2a (Durelli 1994) accounted for only $20(1.6 \%)$ participants. All studies included only relapsing-remitting MS participants. (See table of included studies).

\section{THE AGENTS COMPARED WITH PLACEBO WERE:}

- IFNA-2a: 9.0 MIU self-administered intramuscularly every other day for six months (Durelli 1994), 4.5 or 9.0 MIU administered by study physician subcutaneously three times weekly for six months (Myhr 1999). The dose of 9.0 MIU was used for comparison.

- IFNB-1a:6.0 MIU administered once weekly by the intramuscular route for 104 weeks, by study nurses or local health professionals under the supervision of study personnel (The MSCRG 1996), 6.0 or 12.0 MIU self-administered subcutaneously once a week for 48 weeks (The OWIMS 1999), 6.0 or 12.0 MIU selfadministered subcutaneously three times weekly for two years (The PRISMS 1998). In the last two studies the dose of 12.0 MIU was used for comparison with placebo. In one study (Polman 2003), $0.06,0.6$, or 6 MIU were administered every day by the oral route.

- IFNB-1b: 1.6 or 8.0 MIU self-administered subcutaneously every other day for two years (IFNB MS Group 1993); 0.8 or 4.0 or 8.0 or 16.0 MIU self-administered subcutaneously three times weekly for three years (Knobler 1993). The doses of 8.0 MIU and 16.0 MIU were used in the first and second study respectively.

\section{EXCLUSION CRITERIA}

Exclusion criteria were specified in seven trials (IFNB MS Group 1993; Durelli 1994; The MSCRG 1996; The PRISMS 1998; Myhr 1999; The OWIMS 1999; Polman 2003). The first trial (IFNB MS Group 1993) excluded participants who had been treated with ACTH or prednisone during the 30 days prior to entry or who had received any previous treatment with azathioprine or cyclophosphamide. The second trial (Durelli 1994) excluded participants who had other severe illnesses, participants who had been treated previously with interferon or cytostatic drugs or with ACTH or corticosteroids during three months before entry, and women who were pregnant. The MSCRG (The MSCRG 1996) excluded patients with prior therapy with immunosuppressants, interferon or $\mathrm{ACTH} /$ steroids within two months before study entry; patients with infection or other active disease; patients with progressive MS; those who were pregnant or breastfeeding and those unwilling to practice contraception during the study. The fourth study (The PRISMS 1998) excluded patients who had previously received interferon, lymphoid irradiation, cyclophosphamide or immunomodulatory or immunosuppressive drugs in the 12 months prior to the study. The fifth study (Myhr 1999) excluded patients who were pregnant or breastfeeding; those who were unwilling to practice contraception; those previously treated with interferon or immunosuppressants during the previous year or steroids in the month before randomisation; patients experiencing significant concomitant disease and those who were in the progressive phase of the disease. The OWIMS study (The OWIMS 1999) excluded patients who were pregnant or lactating, patients who were concomitantly ill with other conditions and those who had previously been treated with interferon, cyclophosphamide, lymphoid irradiation or any immunosuppressive or experimental therapy in the preceding twelve months. In the trial testing oral interferon (Polman 2003) patients were excluded if any previous parenteral IFN treatment had been terminated due to inefficacy. In only one study (Knobler 1993) exclusion criteria were not reported.

All trials applied diagnostic criteria for MS (Poser 1983).

Data on the time period of patient recruitment were missing in the Myhr study (Myhr 1999) and in the Polman study (Polman 2003). The scheduled follow-up periods were six months (Durelli 1994), 48 weeks (The OWIMS 1999), 12 months (Myhr 1999), two years (IFNB MS Group 1993; The MSCRG 1996; The PRISMS 1998) and three years (Knobler 1993).

\section{OUTCOMES}

A clinical outcome was the primary outcome measure in five studies: clinical relapse (IFNB MS Group 1993; Knobler 1993; Durelli 
1994; The PRISMS 1998) or disability progression (The MSCRG 1996).

Magnetic resonance imaging was used as the primary outcome measure in two studies (The OWIMS 1999; Myhr 1999) in which clinical outcomes were reported as the secondary outcomes. In the Polman study (Polman 2003) primary outcome was the cumulative number of newly active lesions seen on brain MRI scans; secondary outcomes included volume of enhancing lesions on TI-weighted images each month, lesion volume on T2-weighted images at month 3 and 6 and safety measures.

\section{CLINICAL OUTCOME}

In five trials (Knobler 1993; Durelli 1994; The PRISMS 1998; Myhr 1999; The OWIMS 1999) data were available on the number of participants who continued to experience exacerbations during the first treatment year; and in three trials (IFNB MS Group 1993; The MSCRG 1996; The PRISMS 1998) exacerbations were reported over the two years following randomisation. Comparable definitions of relapse were used in the trials and included:

- acute or subacute objective deterioration of neurological status attributable to the disease, lasting at least 24 hours in the absence of fever and followed by complete or partial resolution (described by Poser 1983)(Durelli 1994);

- a new symptom or worsening of an old symptom accompanied by a new neurologic abnormality, lasting at least 24 hours in the absence of fever and preceded by stability or improvement for at least 30 days (described by Schumacher 1968) (IFNB MS Group 1993; Knobler 1993; The PRISMS 1998; Myhr 1999; The OWIMS 1999);

- a new symptom or worsening of an old symptom of at least 48 hours, which followed clinical stability or improvement of at least 30 days duration (described by Jacobs 1995) (The MSCRG 1996).

Definitions of disease progression were also similar:

- deterioration from baseline $=1.0$ point or more on the Expanded Disability Status Scale (EDSS) persisting for at least six months (The MSCRG 1996);

- increase in EDSS of at least 1.0 point sustained over at least three months (IFNB MS Group 1993; The PRISMS 1998).

In two trials (IFNB MS Group 1993; The PRISMS 1998) the mean disability score (EDSS) was reported as a change of disability with respect to the baseline.

The number of patients who were unable to walk without aid (EDSS score greater than 5.5 ) at the end of the follow-up period was not reported in any trial.

Time from randomisation to first exacerbation was reported as the median time.

Two studies (Durelli 1994; Myhr 1999) reported the number of participants who underwent steroid treatment in the first year after randomisation and one study (The PRISMS 1998) reported participants with steroid treatment within two years of randomisation.

Hospitalisation within two years was included as an outcome in two studies (Durelli 1994; The PRISMS 1998).

\section{SIDE EFFECTS AND ADVERSE EVENTS}

Data concerning the numbers of participants with side effects or adverse events (attributed to interferon during the study according to the authors) were reported in six trials (IFNB MS Group 1993; Durelli 1994; The MSCRG 1996; The PRISMS 1998; Myhr 1999; The OWIMS 1999). One study (Knobler 1993) did not report data for each treatment group, but only gave cumulative numbers for groups that had received different doses of interferon. Finally, it was not possible in any of the trials to assess the length of time for the development of side effects or adverse events, either due to short follow-up periods or because of incomplete reporting.

\section{MAGNETIC RESONANCE IMAGING (MRI)}

Seven trials reported MRI data using a number of different assessments, measures and time of follow-up. One study (IFNB MS Group 1993) reported MRI data for only $60 \%$ of the randomised participants. In another study (The OWIMS 1999) the authors reported the results of MRI, but without the numbers of participants who underwent complete MRI evaluations.

\section{Risk of bias in included studies}

\section{RANDOMISATION}

Concealment of treatment allocation had been adequate in three trials (Durelli 1994; The PRISMS 1998; The OWIMS 1999) and unclear in the other five (Knobler 1993; IFNB MS Group 1993; The MSCRG 1996; Myhr 1999; Polman 2003).

\section{BASELINE PARTICIPANTS' CHARACTERISTICS}

All participants were clinically stable at study entry except in one study which did not report whether or not participants were in a stable phase (The PRISMS 1998). Equivalence between treated and control participants for age, disability score at entry and frequency of exacerbations in the pre-study period was confirmed in all studies except in one which did not report clinical characteristics for each arm (The MSCRG 1996). Disease duration was longer in treated than in control participants in three studies (IFNB MS Group 1993; The PRISMS 1998; Myhr 1999).

\section{BLINDING}

All trials were intended to be double-blind. However the well documented side effects of interferon injection, mainly injectionsite reactions and influenza-like symptoms, make it likely that patients could become unblinded during trials. Analysis of blinding in two studies (IFNB MS Group 1993; The MSCRG 1996) identified a strong tendency for treated patients to become unblinded. Specifically, $80 \%$ of participants in the 8.0 MIU IFNB-1b arm, $51 \%$ in the 1.6 MIU IFNB-1b arm and $30 \%$ in the placebo arm had correctly guessed their treatment at the end of follow-up (IFNB MS Group 1993). Thus many, if not most, treated patients had become aware of the treatment they were receiving during the course of the trial, and these trials should be regarded as single-blind.

\section{PARTICIPANTS LOST TO FOLLOW-UP}

Overall, 246 (19\%) participants were excluded after randomisation or were lost to follow-up (Table 2). In one study (The MSCRG 1996), $73(46 \%)$ of the 158 randomised participants in the treatment group and $56(39 \%)$ of the 143 in the control group did not complete the scheduled two years of follow-up because the study ended prematurely. In this study, the occurrence of acute exacerbations or disease progression were not reported at one year; at two years these primary outcomes were available for only $57 \%$ of the randomised participants. In one trial (IFNB MS Group 1993), 
withdrawals and losses to follow-up were agglomerated into a single figure: 48 participants (19\%).

Participant- or investigator- perceived worsening and side effects or adverse events were the most frequent causes of withdrawn or loss to follow-up in all trials.

\section{INTENTION-TO-TREAT ANALYSIS}

Although an intention-to-treat analysis was mentioned in seven trials (IFNB MS Group 1993; Durelli 1994; The MSCRG 1996; The PRISMS 1998; Myhr 1999; The OWIMS 1999; Polman 2003) in most cases patients who were withdrawn and lost to follow-up had been excluded from the analyses.

\section{Effects of interventions}

\section{PRIMARY OUTCOMES}

(1) THE NUMBER OF PARTICIPANTS WHO CONTINUED TO EXPERIENCE EXACERBATIONS DURING THE FIRST YEAR OF TREATMENT

This information was available from five trials (Knobler 1993; Durelli 1994; The PRISMS 1998; Myhr 1999; The OWIMS 1999) and 667 participants representing $51 \%$ of those included in this review. Eighty five per cent of these participants were from two trials (The PRISMS 1998; The OWIMS 1999). Overall, the risk of new exacerbations in participants receiving interferon was $50 \%$ and the risk of new exacerbations in participants not receiving interferon was $68 \%$. There was significant heterogeneity among the trials (chi $2=8.54, \mathrm{df}=4, \mathrm{p}=0.07$ ). Using a random effects model the pooled relative risk with interferon administration was $0.73,95 \% \mathrm{Cl} 0.55$ to $0.97, p=0.03$, and the pooled risk difference was $-23 \%, 95 \% \mathrm{Cl}$ $-8 \%$ to $-39 \%$ which means that if $100 \mathrm{MS}$ patients were treated with interferon, 23 (95\% Cl 8 to 39) would be free from exacerbations during the first year.

Univariate meta-regression analysis, performed by STATA, identified that the length of interferon administration (number of weeks up to one year) and dose (interferon MIU/week) explained the heterogeneity between the studies. We found no evidence that the type of interferon administered had any effect on the outcome. A subgroup analysis based on the five trials identified little benefit with interferon administered for six months (relative risk $0.82,95 \%$ $\mathrm{Cl} 0.66$ to 1.02, $\mathrm{p}=0.08$ ) (Durelli 1994; Myhr 1999; The OWIMS 1999) than treatment for one year (relative risk $0.69,95 \% \mathrm{Cl} 0.59$ to 0.80 , $\mathrm{p}<0.001$ ) (Knobler 1993; The PRISMS 1998). In four of the trials, the exception was (Durelli 1994), the participants were followed at least for one year. In four of the five studies, participants had MS for five to seven years at randomisation; in the other study (Durelli 1994) mean disease duration was nine years. All participants had a disability score (EDSS) at randomisation between 0 and 5.5 .

The results of the Polman study (Polman 2003) did not indicate a benefit for oral interferon-1a: approximately two-thirds of patients in each group remained relapse free at 6 months follow-up.

(2) THE NUMBER OF PARTICIPANTS WHO CONTINUED TO EXPERIENCE EXACERBATIONS DURING THE FIRST TWO YEARS OF TREATMENT

Data from three trials (IFNB MS Group 1993; The MSCRG 1996; The PRISMS 1998) involving 919 participants ( $71 \%$ of participants included in this review) were available for this outcome measure. The pooled relative risk of exacerbations despite interferon administration was $0.80(95 \% \mathrm{Cl} 0.73$ to $0.88, \mathrm{p}<0.001)$, a decrement of $20 \%$ in the treatment group compared to the control group. There was no heterogeneity between the three trials (chi2 $=0.43, \mathrm{df}=2, \mathrm{p}=0.81$ ). Overall, the risk of exacerbations during the first two years in participants receiving interferon was $55 \%$ and the risk in placebo-treated participants was $69 \%$. The pooled risk difference was $-14 \%(95 \% \mathrm{Cl}-8 \%$ to $-19 \%)$ using a fixed effect model.

The reduction in exacerbations disappeared if interferon-treated participants who dropped out were assumed to have had exacerbations (worst case scenario). In this case, there was a significant heterogeneity between the trials (chi2 $=46.15, \mathrm{df}=2, \mathrm{p}<$ 0.001 ). This was explained by the fact that in one study (The MSCRG 1996) $43 \%$ of the randomised participants did not contribute to the two year data. Using a random effects model the pooled relative risk of exacerbation for participants treated with interferon was 1.11, $95 \% \mathrm{Cl} 0.73$ to $1.68, \mathrm{p}=0.6$.

(3) THE NUMBER OF PARTICIPANTS WHOSE CONDITION PROGRESSED DURING THE FIRST TWO YEARS OF TREATMENT

Data from three trials (IFNB MS Group 1993; The MSCRG 1996; The PRISMS 1998) involving 919 (71\%) participants were available for this outcome. Overall, MS progressed in $20 \%$ of the participants in the interferon arm and $29 \%$ in the placebo arm over two years. There was no heterogeneity between the three trials. This result underlined a benefit of interferon in reducing progression of the disease (relative risk $0.69,95 \% \mathrm{Cl} 0.55$ to $0.87, \mathrm{p}=0.002$ ). It implies that for every 100 people treated, $9(95 \% \mathrm{Cl} 3$ to 14) would be expected to remain stable over two years. However, the assignment of dropouts (to progression or not) was essential to the demonstration of efficacy. If interferon-treated participants who dropped out were assumed to have progressed (worst case scenario) there was a significant heterogeneity between the trials (chi2 $=30.99, \mathrm{df}=2, \mathrm{p}<0.001$ ) explained by the MSCRG study (The MSCRG 1996) and the treatment no longer produced a significant benefit (relative risk 1.31, 95\% $\mathrm{Cl} 0.60$ to $2.89, \mathrm{p}=0.5$ ).

\section{(4) MEAN CHANGE IN DISABILITY SCORE (Expanded Disability Status} Scale) AT TWO YEARS

This outcome was available from only two trials (IFNB MS Group 1993; The PRISMS 1998) involving 618 (51\%) participants included in this review. The effect of the treatment on patient disability (as assessed by Expanded Disability Status Scale) was statistically significant (weighted mean difference $=-0.25,95 \% \mathrm{Cl}-0.05$ to $-0.46, p=0.01$ ). There was no significant heterogeneity between the two studies for this outcome. It should be emphasised that this result is of questionable clinical importance because it would be impossible to measure this very low degree of change on the Expanded Disability Status Scale in the clinical practice.

(5) THE NUMBER OF PARTICIPANTS WHO WERE UNABLE TO WALK WITHOUT AID (Expanded Disability Status Scale greater than 5.5) AT TWO YEARS

No data were available for this outcome.

\section{SECONDARY OUTCOMES}

(a) TIME FROM RANDOMISATION TO THE FIRST EXACERBATION No data were available.

(b) TIME FROM RANDOMISATION TO PROGRESSION IN DISABILITY 
No data were available.

\section{(c) THE NUMBER OF PARTICIPANTS WHO UNDERWENT STEROID TREATMENT}

This information was available during the first year from only two small trials (Durelli 1994; Myhr 1999) involving 85 (7\%) participants included in this review. These two trials differed in duration of follow-up (six months in Durelli and 12 months in Myhr). It is not surprising to find that the results of these two trials were different from one another: the first study showing a reduction (not significant) in the use of steroids in participants receiving interferon and the second study not confirming this beneficial effect.

The frequency of steroid administration over the first two years from randomisation was available from only one study (The PRISMS $1998)$ and 371 (29\%) participants included in this review. The result was significant (relative risk $0.70,95 \% \mathrm{Cl} 0.56$ to $0.87, \mathrm{p}=0.001$ ).

\section{(4) THE NUMBER OF PARTICIPANTS WHO WERE HOSPITALISED OVER TWO YEARS}

This information was available from only two trials (Durelli 1994; The PRISMS 1998) involving 391 (30\%) participants included in this review. Again there was heterogeneity between these two trials (chi2 $=3.48, d f=1, p 0.06$ ). There was no significant reduction in the frequency of hospitalisation between participants treated with interferon and those treated with placebo (relative risk $0.44,95 \% \mathrm{Cl}$ 0.08 to $2.36, p=0.3$ ). Data from another study (IFNB MS Group 1993) were available only after three years. Participation in the third year was optional in that study.

\section{(5) THE NUMBER OF PARTICIPANTS WITH SIDE EFFECTS OR ADVERSE EVENTS ATTRIBUTED TO TREATMENT}

The definitions of side effects or adverse events, as reported by the study authors, are listed in Table 3 .

\section{(a) PARTICIPANTS WHO HAD CLINICAL SIDE EFFECTS OR ADVERSE EVENTS DURING TREATMENT}

Not all results concerning side effects and adverse events were described, monitored and reported in a uniform manner. There were some deviations among studies in the timelines against which side effects were measured and in the definition of composite syndromes, such as "flu-like syndrome" or "flu-like symptoms". This likely accounts for the heterogeneity (chi2 $=12.37, \mathrm{df}=$ $3, p=0.006)$ in the observation of this syndrome, which was interpreted rather vaguely. Heterogeneity was not encountered when its component symptoms (fever, myalgia, fatigue and nausea) were considered individually.

A constellation of "flu-like symptoms" was reported by four studies (IFNB MS Group 1993; The MSCRG 1996; The PRISMS 1998; The OWIMS 1999) involving 1117 (86\%) participants included in this review. These symptoms were experienced by $48 \%$ of participants receiving interferon and $28 \%$ of those receiving placebo: the relative risk was $1.70,95 \% \mathrm{Cl} 1.23$ to $2.37, \mathrm{p}=0.001$ ) using a random effects model. All authors reported that flu-like symptoms diminished after three months of treatment. One author (Durelli 1994) reported that these symptoms were experienced by "several participants" receiving interferon, but usually disappeared the following morning after injection. Another author (Myhr 1999) did not give the frequency of this side effect but reported that one participant in the higher dose interferon group discontinued treatment because of "flu-like" symptoms and an exacerbation.

Fever and myalgias or arthralgias were described as isolated symptoms in six of the studies (IFNB MS Group 1993; Durelli 1994; The MSCRG 1996; The PRISMS 1998; Myhr 1999; The OWIMS 1999) that included 1199 (92\%) participants considered in this review. Fever occurred in $28 \%$ of participants receiving interferon and in $14 \%$ receiving placebo; myalgias or arthralgias in $26 \%$ of treated and $13 \%$ of placebo participants. The risks for fever (relative risk $2.01,95 \% \mathrm{Cl} 1.60$ to $2.52, \mathrm{p}<0.001$ ) and myalgias or arthralgias (relative risk $1.92,95 \% \mathrm{Cl} 1.52$ to $2.43, \mathrm{p}<0.00001$ ) were increased in the treated group.

Fatigue was reported in five of the studies (Durelli 1994; The MSCRG 1996; The PRISMS 1998; Myhr 1999; The OWIMS 1999), involving $952(73 \%)$ participants included in this review. Fatigue occurred in $17 \%$ of participants treated with interferon and $12 \%$ treated with placebo. The risk for fatigue was $1.37(95 \% \mathrm{Cl} 1.01$ to $1.88, \mathrm{p}=0.05)$. In one study (IFNB MS Group 1993) fatigue was the cause for the withdrawal of three participants receiving interferon.

Information on the frequency of nausea and vomiting was available in two studies (The MSCRG 1996; Myhr 1999) involving 363 (28\%) participants included in this review. Participants receiving interferon were at increased risk for this side effect compared to controls (relative risk $1.59,95 \% \mathrm{Cl} 1.11$ to $2.28, \mathrm{p}=0.01$ ) using a fixed effect model.

Headache was reported as an isolated symptom in five studies (Durelli 1994; The MSCRG 1996; The PRISMS 1998; Myhr 1999; The OWIMS 1999) involving 952 (73\%) participants. Headache was experienced by $50 \%$ of participants taking interferon and $42 \%$ taking placebo, and was the reason for one participant withdrawing from one study (IFNB MS Group 1993). The relative risk was 1.16, $95 \% \mathrm{Cl} 1.02$ to $1.33, \mathrm{p}=0.02$, using a fixed effect model.

Injection site reactions: in five studies, interferon was given by the subcutaneous route and in four of these (IFNB MS Group 1993; The PRISMS 1998; Myhr 1999; The OWIMS 1999) the proportion of participants with injection site reactions was reported: $62 \%$ in the participants receiving interferon and $14 \%$ in those receiving placebo. There was significant heterogeneity between these studies (chi2 $=17.75, \mathrm{df}=2, \mathrm{p}<0.0001$ ). This is probably due to the different definitions of injection site reaction and the clinical ascertainment of cutaneous reactions to interferon injection. The relative risk of such reactions, estimated by random effects model, was greater in treated participants $(5.57,95 \% \mathrm{Cl} 2.33$ to $13.29, \mathrm{p}<$ $0.0001)$. The severity of skin reactions was not specified in any of the included trials. Only in two studies which reported them, were there comments on the presence or absence of skin necrosis at the site of injection. This occurred in "1 to 3\% of participants" (IFNB MS Group 1993) or not at all (The OWIMS 1999). In two studies, interferon was given intramuscularly (The MSCRG 1996; Durelli 1994). In the first of these, skin reactions were reported in 10 to $15 \%$ of participants in both treated and control groups and in the second study in none of the participants. The possibility of inadvertent subcutaneous injection was not mentioned.

Hair loss was only described in two studies (Durelli 1994; Myhr 1999) and occurred in $36 \%$ of participants in the interferon group and $2 \%$ in the placebo group: an increased risk of $9.78,95 \% \mathrm{Cl} 1.98$ to 
$48.27, p=0.005)$. In the Myhr study, this symptom affected $40 \%$ of interferon participants over the first six months of treatment.

Dysesthesias, paresthesias and weakness: in one study (Myhr $1999)$ one participant (1/32) in the control group experienced dysesthesias or paresthesias and six participants (4/30 in the interferon group and $2 / 32$ in the placebo group) had weakness.

Depression was assessed and reported in six trials (IFNB MS Group 1993; Durelli 1994; The MSCRG 1996; The PRISMS 1998; Myhr 1999; The OWIMS 1999) and 1199 participants representing 92\% of those included in this review. Depression was reported in $16 \%$ of participants and did not differ between the interferon and control groups. Suicide or attempted suicide was reported by three studies (IFNB MS Group 1993; The MSCRG 1996; The PRISMS 1998) and occurred in seven participants. These events did not differ between the interferon and placebo participants. Only two studies reported data on anorexia (Durelli 1994; Myhr 1999) which was present in three participants.

Muscle hypertonia was reported in one small study (Knobler 1993) and was present at the same frequency in treated and control groups.

Hypertension requiring drug treatment was not reported in any trials included in this review.

\section{(b) PARTICIPANTS WHO HAD ABNORMAL VALUES DURING TREATMENT}

Lowered hemoglobin levels values were reported in three studies (Durelli 1994; The MSCRG 1996; Myhr 1999) and 383 (29\%) participants included in this review. This event occurred more frequently in participants receiving interferon than controls $(3.5 \%$ versus $1 \%$ ) but the increased risk was not statistically significant.

Leukopenia was reported in five studies (IFNB MS Group 1993; Durelli 1994; The MSCRG 1996; The PRISMS 1998; Myhr 1999) and $1004(77 \%)$ participants. It was found in $6 \%$ of participants in the interferon group and $0.6 \%$ in the control group, with a significantly increased risk for treated participants (relative risk $6.47,95 \% \mathrm{Cl} 2.43$ to $17.20, p<0.001$ ).

Lymphopenia was reported in two studies (IFNB MS Group 1993; The PRISMS 1998) and $618(48 \%)$ participants included in this review. It occurred in $27 \%$ of participants receiving interferon and $14 \%$ receiving placebo, a significantly increased risk for treated participants (relative risk $2.16,95 \% \mathrm{Cl} 1.01$ to $4.64, \mathrm{p}=0.05$, using a random effects model.

Thrombocytopenia was described in three studies (Durelli 1994; The MSCRG 1996; Myhr 1999) and 383 (29\%) participants. The risk for this side effect was greater in treated participants in only one of these studies (Myhr 1999). Myhr reported that the proportion of participants experiencing thrombocytopenia was $23 \%$ in the interferon group and $3 \%$ in the placebo group.

The values of two hepatic enzymes in blood were reported. Aspartate aminotransferase (AST) was reported in three studies (IFNB MS Group 1993; The MSCRG 1996; The PRISMS 1998) and 919 (71\%) participants, and alanine aminotransferase (ALT) in four studies (IFNB MS Group 1993; The MSCRG 1996; The PRISMS 1998; Myhr 1999) and 981 (75\%) participants. Increased AST and ALT occurred more frequently in participants who received interferon
(4\% and 9\%) than controls (1\% and 3\%). Participants treated with interferon had a higher risk both for increased AST (relative risk $2.83,95 \% \mathrm{Cl} 1.14$ to $7.06, \mathrm{p}=0.03$ ) and $\mathrm{ALT}$ (relative risk $3.57,95 \% \mathrm{Cl}$ 1.98 to $6.43, p<0.0001$, using a fixed effect model).

Neutralizing antibodies (NAB) against interferon developed in approximately $20 \%(83 / 421)$ of the treated participants in whom this parameter was assessed (IFNB MS Group 1993; Knobler 1993; The MSCRG 1996; The PRISMS 1998; The OWIMS 1999; Myhr 1999). The nature of the biological assays was different and the definitions of positive titres were variable between the studies. When assays were performed the timing and sample sizes were often not reported. Antibodies developed most commonly in the first treatment year. Neutralizing antibodies were only rarely reported in placebo-treated participants.

\section{(6) MAGNETIC RESONANCE IMAGING (MRI)}

There was a significant evolution in the application of MRI technology in the decade in which these trials were conducted and it was not possible to make comparisons across the trials from published data. Different measures of MRI were used and reported in the included trials, often on small samples of randomised participants and at different times of follow-up. For these reasons, we therefore present a qualitative summary of MRI findings (Table 4). In each trial, lesion activity was measured somewhat differently, commonly without reported measures of variance. An analysis of changes in T2 burden was possible only for the trials of interferon beta 1b (IFNB MS Group 1993) and the PRISMS (The PRISMS 1998).

Unpublished data (mean change in T2 burden, standard deviation) were provided by the sponsor of these two trials who reported a significant reduction in $\mathrm{T} 2$ burden aggregating both studies (weighted mean difference $-24.67,95 \% \mathrm{Cl}-33.84$ to $-15.50, \mathrm{p}<$ 0.001 ). Numerical data on this aspect were not available for the MSCRG study, in which a significant effect on the change in T2 burden was not found at the end of the second year of the study (The MSCRG 1996).

Data on gadolinium enhancing lesions were available from two studies (The MSCRG 1996; Myhr 1999) after one year of treatment and from one study after two years of treatment on a small sample of randomised participants (The MSCRG 1996). A reduction in gadolinium enhancement was evident at one year but not at two years. In individual studies, treatment with recombinant interferon was associated with reductions in other MRI measures, such as the number of new $\mathrm{T} 2$ or enlarging lesions.

No significant differences in new active lesions were observed between the oral interferon-1a and control groups (Polman 2003).

\section{NUMBERS NEEDED TO TREAT}

The estimates of numbers needed to treat to prevent one patient having at least one exacerbation at 1 year in relation to the baseline risks are shown in Table 5. This figure shows, for example, that nine patients needed to be treated to prevent one patient having at least one exacerbation at 1 year when the risk of recurrence was $40 \%$ in the multiple sclerosis population.

\section{DISCUSSION}

The results support a modest protective effect of interferon against recurrence of exacerbations during the first two years of treatment 
Treatment of patients with interferon was associated with a $20 \%$ reduction in the relative risk of having attacks. Sensitivity analysis indicates that this value is likely true, considering the intermediate between the "best" and the "worst" case scenario. Interferon administered by the oral route is not effective for prevention of relapses.

We chose the proportion of participants who continued to experience exacerbations as the principal outcome rather than the more commonly reported "annualised exacerbation rate". The principal reason for this was that these annualised rates were not reported with a measure of the variance of the observation. Also, the reporting of annualised exacerbation rates could overestimate the extent of a treatment effect. Unusually high rates of exacerbations in individuals who were treated with placebo could embellish the "annualised rate" for the group (The MSCRG 1996). Reporting the absolute numbers of participants who continued to experience exacerbations, despite treatment, is a more meaningful estimation of the shouldering of the treatment effect in a treated population.

The need for steroid treatment did not decrease for participants treated with interferon during the first or the second year after randomisation. In the interferon beta $1 \mathrm{~b}$ trial, a claim was made that steroid treatments were reduced but the authors did not report the data. Disconcertingly, these data were missing in the other trials, given the strength of the claims that interferon suppressed clinical attacks.

Hospitalisation was not significantly reduced in two trials that reported on this aspect; however this could have been to some extent related to the major shift to outpatient management of exacerbations that occurred in the decade of these trials.

Interferon treatment was associated with a reduction in the number of participants whose MS condition progressed. This effect was identified in three trials (IFNB MS Group 1993; The MSCRG 1996; The PRISMS 1998). To calculate the effect, we tallied the number of participants who fulfilled the definition for progression at the end of two years. The effect was significant (relative risk $0.69,95 \%$ $\mathrm{Cl} 0.55$ to $0.87, \mathrm{p}=0.002$ ). However, this effect of interferon on the prevention of disease progression could clearly be influenced by inappropriate consideration of dropouts. If all dropouts in the treated group were assumed to have progressed, the significance of the effect disappeared (relative risk $1.31,95 \% \mathrm{Cl} 0.60$ to 2.89 , $\mathrm{p}=0.5$ ). Only in the interferon beta $1 \mathrm{~b}$ study was the disability status of dropouts mentioned in any detail: the participants who dropped out of that trial experienced higher exacerbation rates, a greater accumulation of disability, and more disease activity on the magnetic resonance imaging. There was a very modest support for an effect on disability by examination of the mean change in disability scores between randomisation and the end of the second year.

In this review, it was not possible to ascertain if the decreased number of participants whose condition progressed was independent from the effect of interferon on exacerbations. Two issues regarding this should be considered. First, is possible that interferon reducing the MS exacerbation could contribute to a perception that treatment prevented unremitting disability (Rice 1998). The probability of not progressing in disability over time was evaluated by survival analysis (Kaplan-Meier curves) in the trials which included this outcome (IFNB MS Group 1993; The
MSCRG 1996; The PRISMS 1998). Once participants worsen and have a subsequent confirmation of disease worsening (generally after three to six months, depending on the study) they do not contribute any further information to a survival analysis. Later improvement would suggest that patients were experiencing severe exacerbations with slow recovery, rather than unremitting disease progression. The extent to which this might have occurred in these trials is unknown. In the MSCRG study, 50\% of interferontreated patients who worsened in the first year of the study, actually improved in the second year (Rice 1998). The MSCRG study investigators made a substantial claim that interferon treatment prevented disability, when the reported effect might have been actually the effect on exacerbations. The error rates in application of "confirmed disability" definitions is substantial (Liu 2000). Another weakness of the disability claims should be identified. Most participants in these randomised trials had low disability scores at entry. The lower range of the disability scale (Expanded Disability Status Scale) is derived from a composite of the neurological examination and scoring in the lower echelons is fraught with high inter- and intra-rater variability (Goodkin 1992). Missing from all the trials was a sense of how often worsening was based on a subscale that is convincingly associated with disability, such as sustained worsening on a pyramidal or cerebellar subscale.

It was anticipated that the effect of interferon on exacerbations and disability in patients with relapsing remitting MS would produce a similar effect on these outcomes in the clinical trials of progressive MS patients. However, this does not appear to be the case. Large clinical trials of interferons in progressive MS have reported modest (European Group 1998; Cohen 2001) or no effect (Goodkin 2000; Hughes 2000) on disability outcomes. The failure of interferons to convincingly prevent disease progression in progressive MS, despite slight effects on exacerbations, has focused attention on the relevance of exacerbations to disease progression. It has been suggested that a high frequency of exacerbations in the early years of the illness is associated with a more severe disease course in the long term (Weinshenker 1989) whereas others have suggested that the disease progression is not influenced by superimposed attacks during the course of the disease (Confavreux 2000).

An influenza-like reaction was very common in treated patients, and injection site reactions were common in those who received interferon subcutaneously. Patients treated with interferon had leukopenia, lymphopenia, thrombocytopenia and increased plasma hepatic enzymes. Both clinical and laboratory side effects were more frequent in patients treated with interferon than in controls.

Depression and depressive symptoms did not appear to be a major problem in the first two years of treatment with interferon across the trials in which this information was available. This potential side effect may have been minimised by greater sensitivity concerning it subsequent to the reporting of the trial of interferon beta $1 b$ (IFNB MS Group 1993).

The impact of these side effects and adverse events on the quality of life of the participants was not reported in any of the trials included in this review.

In order to assess the impact of interferon in clinical practice, the number of participants who need to be treated to prevent one unfavourable outcome (NNT) has also been determined. This measure is generally calculated as the reciprocal of absolute risk 
differences. However, weighted absolute risk differences estimated from meta-analysis are applicable only to patients who are at the risk level corresponding to the average risk of the trial participants, and this may not be relevant to individual clinical situations (Smeeth 1999). Therefore we chose to show a full range of possible NNT according to different values of patient baseline risk for the principal outcomes.

Neutralizing antibodies against interferon developed in 83 of the 421 participants treated with interferon in whom this parameter was assessed. As there were differences between the studies with regard to the type of antibody assay, and definitions of antibody positive titers, it was impossible to perform a quantitative analysis on this aspect. Similarly, because of inconsistent reporting of an effect of these antibodies on clinical outcomes, it was not possible to evaluate a deleterious effect on the major outcomes. Since neutralizing antibodies tend to appear in the first year of treatment, an effect would not be expected until the second or third year of study. Most trials have not been adequately powered in the second and third year of study to show this effect.

\section{AUTHORS' CONCLUSIONS}

\section{Implications for practice}

We found a modest effect in patients with relapsing remitting MS, treated with interferon, in reducing exacerbations and disability. Information on the frequency and severity of side effects and adverse events was limited to a follow-up period of two years.

\section{Implications for research}

Due to inconsistent data reporting among these trials, it was impossible to conduct all of the intended analyses. More randomised clinical trials are needed to answer the following questions:

- Is there a convincing effect from interferon on disability in patients with MS?

- Does treatment with interferon improve the quality of life of the patient?

- How durable are the effects on clinical outcome?

- How long should patients be treated?

- What is the optimum dose and type of interferon?

- Are there long term side effects and adverse events?

- Are neutralising antibodies relevant to drug efficacy?

Given the substantial expense of these drugs, these are important questions of immense clinical relevance.

Finally, there is an urgent need to develop a general consensus regarding the quality of reporting of trial results in the MS literature.

\section{ACKNOWLEDGEMENTS}

Authors wish to thank Prof Jon Deeks (Centre for Statistics in Medicine, Institute of Health Sciences, Oxford UK), Prof Alessandro Liberati and Ms Elena Telaro (Italian Cochrane Centre), Dr Bernard MJ Uitdehaag (VU Medical Centre, Amsterdam, The Netherlands), Prof Silvio Garattini and Dr Walter Torri (Istituto di Ricerche "Mario Negri", Milan Italy), Prof Alan Thompson (Department of Clinical Neurology, National Hospital for Neurology and Neurosurgery, London, UK), Prof Silvana Simi, Prof Daniela Lupo and Mr Lorenzo Brait (participant consumers of the Cochrane MS Group) for useful comments during the preparation of the manuscript. 


\section{REFERE N CES}

\section{References to studies included in this review}

\section{Durelli 1994 \{published data only\}}

Bongioanni MR, Durelli L, Ferrero B, Imperiale D, Oggero A, Verdun $\mathrm{E}$, et al. Systemic high-dose recombinant-alpha-2ainterferon therapy modulates lymphokine production in multiple sclerosis. Journal of the Neurological Sciences 1996;143(1-2):91-9. [MEDLINE: 97135767; EMBASE-1996367643]

* Durelli L, Bongioanni MR, Cavallo R, Ferrero B, Ferri R, Ferrio MF, et al. Chronic systemic high-dose recombinant interferon alfa-2a reduces exacerbation rate, MRI signs of disease activity, and lymphocyte interferon gamma production in relapsing-remitting multiple sclerosis. Neurology 1994;44(3 Pt 1):406-13. [MEDLINE: 94195489; EMBASE-94096622]

Durelli L, Bongioanni MR, Ferrero B, Ferri R, Imperiale D, Bradac GB, et al. Interferon alpha-2a treatment of relapsingremitting multiple sclerosis: disease activity resumes after stopping treatment. Neurology 1996;47(1):123-9. [MEDLINE: 96291029; EMBASE-1996221919]

Durelli L, Bongioanni MR, Ferri R, Cavallo R, Aimo G, Ferrero B, et al. Interferon (IFN)-Alpha 2a treatment of relapsing-remitting $(\mathrm{R} / \mathrm{R})$ multiple sclerosis (MS): disease activity resumes after stopping treatment [Abstract]. Neurology 1994;44 Suppl (2):A358.

\section{IFNB MS Group 1993 \{published data only\}}

Arnason BGW. Interferon beta in multiple sclerosis [Editorial]. Neurology 1993;43(4 Pt 1):641-3. [EMBASE-1993121948]

Broderick JP, Samaha FJ. Interferon beta treatment of multiple sclerosis [Letter]. Neurology 1994;44(1):186. [MEDLINE: 94119382; EMBASE-1994036622]

Ebers GC, Lublin F, Paty D, Reder A. Treatment of multiple sclerosis with interferon beta-1b [Letter]. Neurology 1997;49:641-2.

Klapper JA. Interferon beta treatment of multiple sclerosis [Letter]. Neurology 1994;44(1):188. [MEDLINE: 94119389; EMBASE-1994036622]

Longstreth WT Jr, Franklin GM. Interferon beta treatment of multiple sclerosis [Letter]. Neurology 1994;44(1):187. [MEDLINE: 94119387; EMBASE-1994036622]

Metz L, Bell R, Zochodne D. Interferon beta treatment of multiple sclerosis [Letter]. Neurology 1994;44(1):187-8. [MEDLINE: 94119388; EMBASE-1994036622]

Pachner AR. Anticytokine antibodies in beta-interferon-treated patients [Letter]. Neurology 1998;50(6):1931-2. [MEDLINE: 98295536; EMBASE-1998205394]

Pachner AR. Interferon beta treatment of multiple sclerosis [Letter]. Neurology 1994;44(1):188. [MEDLINE: 94119390; EMBASE-1994036622]
Packner AR. Anticytokine antibodies in beta interferon-treated patients and the need for testing: plight of the practicing neurologist. Neurology 1997;49(3):647-50. [MEDLINE: 97450328]

Paty DW, Li DKB, the UBC MS/MRI Study Group, the IFNB Multiple Sclerosis Study Group. Interferon beta- $1 b$ is effective in relapsing-remitting multiple sclerosis. II. MRI analysis results of a multicenter, randomized, double-blind, placebo-controlled trial. UBC MS/MRI Study Group and the IFNB Multiple Sclerosis Study Group. Neurology 1993;43(4):662-7. [MEDLINE: 93226095; EMBASE-93121952]

Petkau J, White R. Neutralizing antibodies and the efficacy of interferon beta- $1 \mathrm{~b}$ in relapsing remitting multiple sclerosis. Multiple Sclerosis 1997;3(6):402. [MEDLINE: 98152637; EMBASE-1998027511]

Rice GPA, Paszner B, Oger J, Lesaux J, Paty D, Ebers G. The evolution of neutralizing antibodies in multiple sclerosis patients treated with interferon beta-1b. Neurology 1999;52:1277-9.

Sibley W, Paty D, Rice GPA, Masuoka LK. Anticytokine antibodies in beta-interferon-treated patients [Letter]. Neurology 1998;50(6):1930-2. [MEDLINE: 98295535; EMBASE-1998205394]

Sibley WA, Ebers G, Panitch HS, Reder AT. Interferon beta treatment of multiple sclerosis [Letter]. Neurology 1994;44(1):188-90. [MEDLINE: 94119393; EMBASE-1994036622]

* The IFNB Multiple Sclerosis Study Group. Interferon beta-1b is effective in relapsing-remitting multiple sclerosis. I. Clinical results of a multicenter, randomized, double-blind, placebocontrolled trial. Neurology 1993;43(4):655-61. [MEDLINE: 93226094; EMBASE-93226094]

The IFNB Multiple Sclerosis Study Group and the University of British Columbia MS/MRI Analysis Group. Interferon beta-1b in the treatment of multiple sclerosis: final outcome of the randomized controlled trial. Neurology 1995;45(7):1277-85. [MEDLINE: 95342398; EMBASE-95224550]

The IFNB Multiple Sclerosis Study Group and the University of British Columbia MS/MRI Analysis Group. Neutralizing antibodies during treatment of multiple sclerosis with interferon beta-1b: experience during the first three years. Neurology 1996;47(4):889-94. [MEDLINE: 97010681; EMBASE-1996330779]

\section{Knobler 1993 \{published data only\}}

Knobler RL, Greenstein JI, Johnson KP, Lublin FD, Panitch HS, Conway $\mathrm{K}$, et al. Systemic recombinant human interferon-beta treatment of relapsing-remitting multiple sclerosis: pilot study analysis and six-year follow-up. Journal of Interferon Research 1993;13(5):333-40. [MEDLINE: 94132656; EMBASE-94358097]

\section{Myhr 1999 \{published data only\}}

Myhr KM, Riise T, Green Lilleas FE, Beiske TG, Celius EG, Edland $A$, et al. Interferon-alpha2a reduces MRI disease activity in relapsing-remitting multiple sclerosis. Norwegian Study 
Group on Interferon-alpha in Multiple Sclerosis. Neurology 1999;52(5):1049-56. [MEDLINE: 99200550; EMBASE-1999124033]

\section{Polman 2003 \{published data only\}}

Polman C, Barkhof F, Kappos L, Pozzilli C, Sandbrink R, Dahlke F, et al. Oral interferon beta-la in relapsing-remitting multiple sclerosis: a double-blind randomized study. Multiple Sclerosis 2003;9:342-48.

\section{The MSCRG 1996 \{published data only\}}

Jacobs LD, Cookfair DL, Rudick RA, Herndon RM, Richert JR, Salazar AM, et al. A phase III trial of intramuscular recombinant interferon beta as treatment for exacerbating-remitting multiple sclerosis: design and conduct of study and baseline characteristics of patients. Multiple Sclerosis Collaborative Research Group (MSCRG). Multiple Sclerosis 1995;1(2):118-35. [MEDLINE: 98005322]

* Jacobs LD, Cookfair DL, Rudick RA, Herndon RM, Richert JR, Salazar AM, et al. Intramuscular interferon beta-1a for disease progression in relapsing multiple sclerosis. The Multiple Sclerosis Collaborative Research Group (MSCRG). Annals of Neurology 1996;39(3):285-94. [MEDLINE: 96180905; EMBASE-1996105672]

Rudick RA, Fisher E, Lee JC, Simon J, Jacobs L, Munschauer III FE, et al. Use of the brain parenchymal fraction to measure whole brain atrophy in relapsing-remitting MS. Multiple Sclerosis Collaborative Research Group. Neurology 1999;53(8):1698-704. [MEDLINE: 20025139; EMBASE-1999394535]

Rudick RA, Goodkin DE, Jacobs LD, Cookfair DL, Herndon RM, Richert JR, et al. Impact of interferon beta-1a on neurologic disability in relapsing multiple sclerosis. The Multiple Sclerosis Collaborative Research Group (MSCRG). Neurology 1997;49(2):358-63. [MEDLINE: 97416612; EMBASE-97265436]

Simon JH, Jacobs LD, Campion M, Wende K, Simonian N, Cookfair DL, et al. Magnetic resonance studies of intramuscular interferon beta-1a for relapsing multiple sclerosis. The Multiple Sclerosis Collaborative Research Group. Annals of Neurology 1998;43(1):79-87. [MEDLINE: 98111247; EMBASE-1998090133]

Simon JH, Jacobs LD, Campion MK, Rudick RA, Cookfair DL, Herndon RM, et al. A longitudinal study of brain atrophy in relapsing multiple sclerosis. The Multiple Sclerosis Collaborative Research Group (MSCRG). Neurology 1999;53(1):139-48. [MEDLINE: 99335035; EMBASE-1999247274]

\section{The OWIMS 1999 \{published data only\}}

The Once Weekly Interferon for MS Study Group (OWIMS). Evidence of interferon beta-1a dose response in relapsingremitting MS. The OWIMS Study. Neurology 1999;53(4):679-86. [MEDLINE: 99417151; EMBASE-1999332822]

\section{The PRISMS 1998 \{published data only\}}

Ebers GC. Interferon beta treatment for multiple sclerosis [Letter]. Lancet 1999;353(9151):497. [MEDLINE: 99142850; EMBASE-1999051720]

Li DKB, Paty DW, the UBC MS/MRI Analysis Research Group, the PRISMS Study Group. Magnetic resonance imaging results of the PRISMS trial: a randomized, double-blind, placebocontrolled study of interferon-beta1a in relapsing-remitting multiple sclerosis. Prevention of Relapses and Disability by Interferon-beta1a Subcutaneously in Multiple Sclerosis. Annals of Neurology 1999;46(2):197-206. [MEDLINE: 99371485; EMBASE-1999285158]

* The PRISMS (Prevention of Relapses and Disability by Interferon beta-1a Subcutaneously in Multiple Sclerosis) Study Group. Randomised double-blind placebo-controlled study of interferon beta-1a in relapsing/remitting multiple sclerosis. Lancet 1998;352(9139):1498-504. [MEDLINE: 99036183; EMBASE-1998379966]

\section{References to studies excluded from this review}

AUSTIMS 1989 \{published data only\}

The AUSTIMS Research Group. Interferon-alpha and transfer factor in the treatment of multiple sclerosis: a double-blind, placebo-controlled trial. AUSTIMS Research Group. Journal of Neurology, Neurosurgery \& Psychiatry 1989;52(5):566-74. [MEDLINE: 89279360; EMBASE-1989151752]

\section{Granger 2003 \{published data only\}}

Granger CV, Wende K, Brownscheidler CM. Use of the FIM instrument in a trial of intramuscular interferon beta-la for disease progression in relapsing-remitting multiple sclerosis. American Journal of Phisical Medicine \& Rehabilitation 2003;82(6):427-36.

\section{Herndon 1999 \{published data only\}}

Herndon RM, Jacobs LD, Coats ME, Goodkin DE, Mass MK, Richert JR, et al. Results of an ongoing, open-label, safetyextension study of interferon beta-1a (Avonex) treatment in multiple sclerosis. International Journal of MS Care 1999;1(2):1-6.

\section{Hirsch 1986 \{published data only\}}

Hirsch RL, Johnson KP. The effects of long-term administration of recombinant alfa- 2 interferon on lymphpcyte substes, proliferation, and suppressor cell function in multiple sclerosis. Journal of Interferon Research 1986;6(2):171-7. [MEDLINE: 86252599]

\section{Jacobs 2000 \{published data only\}}

Jacobs LD, Beck RW, Simon JH, Kinkel RP, Brownscheidle CM, Murray TJ. Intramuscular interferon beta-1a therapy initiated during a first demyelinating event in multiple sclerosis. New England Journal of Medicine 2000;343(13):898-904.

Knobler 1984 \{published data only\}

Knobler RL, Panitch HS, Braheny SL, Sipe JC, Rice GP, Huddlestone JR, et al. Clinical trial of natural alpha interferon in multiple sclerosis. Annals of the New York Academy of Sciences 1984;436:382-8.

\section{Milanese 1990 \{published data only\}}

Milanese C, Salmaggi A, La Mantia L, Campi A, Eoli M, Savoiardo M, et al. Double blind study of intrathecal betainterferon in multiple sclerosis: clinical and laboratory 
results. Journal of Neurology, Neurosurgery \& Psychiatry 1990;53(7):554-7. [MEDLINE: 90362109; EMBASE-90245871]

\section{Pozzilli 1997 \{published data only\}}

Koudriavtseva T, Pozzilli C, Fiorelli M, Gasperini C, Bagnato F, Galgani S, et al. Determinants of Gd-enhanced MRI response to IFN-beta-1a treatment in relapsing-remitting multiple sclerosis. Multiple Sclerosis 1998;4(5):403-7. [MEDLINE: 99056678; EMBASE-1998381761]

Paolillo A, Bastianello S, Frontoni M, Gasperini C, Giugni E, Ciccarelli $\mathrm{O}$, et al. Magnetic resonance imaging outcome of new enhancing lesions in relapsing-remitting multiple sclerosis patients treated with interferon beta-1a. Journal of Neurology 1999;246(6):443-8. [MEDLINE: 99358715; EMBASE-1999244760]

* Pozzilli C, Bastianello S, Koudriatseva T, Gasperini C, Mainero C, Giugni E, et al. An open randomised trial with two different doses of recombinant interferon beta-1a in relapsingremitting multiple sclerosis: clinical and MRI results at 24 months [Abstract]. Journal of Neurology 1997;244:S25.

Pozzilli C, Bastianello S, Koudriavtseva T, Gasperini C, Bozzao A, Millefiorini $\mathrm{E}$, et al. Magnetic resonance imaging changes with recombinant human interferon-beta-1a: a short term study in relapsing-remitting multiple sclerosis. Journal of Neurology, Neurosurgery \& Psychiatry 1996;61(3):251-8. [MEDLINE: 96388194; EMBASE-1996271523]

\section{Rudge 1995 \{published data only\}}

Rudge P, Miller D, Crimlisk H, Thorpe J. Does interferon beta cause initial exacerbation of multiple sclerosis? [Letter]. Lancet 1995;345(8949):580. [MEDLINE: 95295442; EMBASE-1995077181]

\section{Rudick 1998 \{published data only\}}

Rudick RA, Simonian NA, Alam JA, Campion M, Scaramucci JO, Jones $W$, et al. Incidence and significance of neutralizing antibodies to interferon beta-1a in multiple sclerosis. Multiple Sclerosis Collaborative Research Group (MSCRG). Neurology 1998;50(5):1266-72. [MEDLINE: 98255412; EMBASE-1998175405]

\section{Schwartz 1997 \{published data only\}}

Schwartz CE, Coulthard-Morris L, Cole B, Vollmer T. The quality-of-life effects of interferon beta-1b in multiple sclerosis. An extended Q-TWIST analysis. Archives of Neurology 1997;54(12):1475-80. [MEDLINE: 98062884; EMBASE-1997379054]

\section{Simon 1999 \{published data only\}}

Simon JH, Jacobs LD, Campion MK, Rudick RA, Cookfair DL, Herndon RM, et al. A longitudinal study of brain atrophy in relapsing multiple sclerosis. The Multiple Sclerosis Collaborative Research Group (MSCRG). Neurology 1999;53(1):139-48. [MEDLINE: 99335035; EMBASE-1999247274]

\section{References to studies awaiting assessment}

\section{Abdul-Ahad 1997 \{published data only\}}

Abdul-Ahad AK, Galazka AR, Revel M, Biffoni M, Borden ED. Incidence of antibodies to interferon-beta in patients treated with recombinant human interferon-betala from mammalian cells. Cytokines Cellular \& Molecular Therapy 1997;3(1):27-32. [MEDLINE: 97432414; EMBASE-1997288646]

Camenga 1986 \{published data only\}

Camenga DL, Johnson KP, Alter M, Engelhardt CD, Fishman PS, Greenstein JI, et al. Systemic recombinant alfa-2 interferon therapy in relapsing multiple sclerosis. Archives of Neurology 1986;43(12):1239-46. [MEDLINE: 87048244]

Edwards 1998 \{published data only\}

Edwars S, Zvartau M, Clarke H, Irving W, Blumhardt LD. Clinical relapses and disease activity on magnetic resonance imaging associated with viral upper respiratory tract infections in multiple sclerosis. Journal of Neurology Neurosurgery \& Psychiatry 1998;64(4):736-41. [MEDLINE: 98309516; EMBASE-1998198807]

\section{Additional references}

\section{Barnes 1997}

Barnes D, Hughes RA, Morris RW, Wade-Jones O, Brown P, Britton T, et al. Randomised trial of oral and intravenous methylprednisolone in acute relapses of multiple sclerosis. Lancet 1997;349(9056):902-6. [MEDLINE: 97247116; EMBASE-1997097394]

\section{Clarke 2000}

Clarke M, Oxman AD, editors. Cochrane Reviewers' Handbook [updated July 1999]; Section 6.3. In: The Cochrane Library [database on CDROM]. The Cochrane Collaboration. Oxford: Update Software; 2000.

\section{Cohen 2001}

Cohen JA, Cutter GR, Fischer JS, Goodman AD, Heidenreich FR, Jak AJ, et al. Use of the multiple sclerosis functional composite as an outcome measure in a phase 3 clinical trial. Archives of Neurology 2001;58(6):961-7. [MEDLINE: 11405811]

\section{Confavreux 2000}

Confavreux C, Vukusic S, Moreau T, Adeleine P. Relapses and Progression of Disability in Multiple Sclerosis. New England Journal of Medicine 2000;343(20):1430-8.

\section{DerSimonian 1986}

DerSimonian R, Laird N. Meta-analysis in clinical trials. Controlled Clinical Trials 1986;7:177-88.

\section{European Group 1998}

European Study Group on Interferon beta-1b in Secondary Progressive MS. Placebo-controlled multicentre randomized trial of interferon beta- $1 \mathrm{~b}$ in treatment of secondary progressive multiple sclerosis. Lancet 1998;52:491-7.

\section{Goodkin 1992}

Goodkin DE, Cookfair D, Wende K, Bourdette D, Pullicino P, Scherokman B, et al. Inter- and intrarater scoring agreement using grades 1.0 to 3.5 of the Kurtzke Expanded Disability Status Scale (EDSS). Multiple Sclerosis Collaborative Research Group. Neurology 42;4:859-63. [MEDLINE: 92228182] 


\section{Goodkin 2000}

Goodkin DE and the North American Study Group on Interferon beta-1b in Secondary Progressive MS. Interferon beta-1b in secondary progressive MS: clinical and MRI results of a 3-year randomized controlled trial [Abstract]. American Academy of Neurology 2000.

\section{Hauser 1983}

Hauser SL, Dawson DM, Lehrich JR, Beal MF, Kevy SV, Propper RD, et al. Intensive immunosuppression in progressive multiple sclerosis. A randomized, three-arm study of high-dose intravenous cyclophosphamide, plasma exchange, and ACTH. New England Journal of Medicine 1983;308(4):173-80. [MEDLINE: 83088812]

\section{Hohlfeld 1997}

Hohlfeld R. Biotechnological agents for the immunotherapy of multiple sclerosis. Principles, problems and perspectives [Review]. Brain 1997;120(Pt 5):865-916. [MEDLINE: 97326435; EMBASE-1997157798]

\section{Hughes 2000}

Hughes RAC and the SPECTRIMS group. Relapsing versus nonrelapsing SPMS: different prognosis and response to interferon therapy in the SPECTRIMS study. Neurology 2000;54 Suppl (3):A233.

\section{Jacobs 1981}

Jacobs L, O'Malley J, Freeman A, Ekes R. Intrathecal interferon reduces exacerbations of multiple sclerosis. Science 1981;214(4524):1026-8. [MEDLINE: 82061836]

\section{Knobler 1984a}

Knobler RL, Panitch HS, Braheny SL, Sipe JC, Rice GP, Huddlestone JR, et al. Systemic alpha-interferon therapy of multiple sclerosis. Neurology 1984;34(10):1273-9. [MEDLINE: 85013159]

\section{Kurtzke 1961}

Kurtzke JF. On the evaluation of disability in multiple sclerosis. Neurology 1961;11:686-94.

\section{Kurtzke 1983}

Kurtzke JF. Rating neurological impairment in multiple sclerosis: an expanded disability status scale (EDSS). Neurology 1983;33(11):1444-52. [MEDLINE: 84040263]

\section{Liu 2000}

Liu C, Blumhardt LD. Disability outcome measures in therapeutic trials of relapsing-remitting multiple sclerosis: effects of heterogeneity of disease course in placebo cohorts. Journal of Neurology, Neurosurgery \& Psychiatry 2000;68(4):450-7. [MEDLINE: 20193717; EMBASE-2000163002 EMBASE-2000163002]

\section{CHARACTERISTICS OF STUDIES}

Characteristics of included studies [ordered by study ID]

\section{Noseworthy 1999}

Noseworthy $\mathrm{JH}$. Progress in determining the causes and treatment of multiple sclerosis [Review]. Nature 1999;399(6738 Suppl):40-7. [MEDLINE: 99319750; EMBASE-1999223163]

\section{Poser 1983}

Poser CM, Paty DW, Scheinberg L, McDonald WI, Davis FA, Ebers GC, et al. New diagnostic criteria for multiple sclerosis: guidelines for research protocols. Annals of Neurology 1983;13(3):227-31. [MEDLINE: 83202737]

\section{Rice 1998}

Rice G, Ebers G. Interferons in the treatment of multiple sclerosis: do they prevent the progression of the disease? Archives of Neurology 1998;55(12):1578-80. [MEDLINE: 99081403]

\section{Schumacher 1968}

Schumacher GA, Beebe G, Kilber RF, et al. Problems of experimental trials of therapy in MS: report of the panel on evaluation of experimental trials in MS. Annals of the New York Academy of Sciences 1968;122:552-68.

\section{Smeeth 1999}

Smeeth L, Haines A, Ebrahim S. Numbers needed to treat derived from meta-analyses- sometimes informative, usually misleading. British Medical Journal 1999;318:1548-51.

\section{vanBoxel-Dezaire2000}

van Boxel-Dezaire AH, van Trigt-Hoff SC, Killestein J, Schrijver HM, van Houwelingen JC, Polman $\mathrm{CH}$, et al. Contrasting responses to interferon beta- $1 \mathrm{~b}$ treatment in relapsing-remitting multiple sclerosis: does baseline interleukin-12p35 messenger RNA predict the efficacy of treatment ?. Annals of Neurology 2000;48(3):313-22. [MEDLINE: 20431149; EMBASE-2000315459]

\section{Weinshenker 1989}

Weinshenker BG, Bass B, Rice GP, Noseworthy J, Carriere W, Baskerville J, et al. The natural history of multiple sclerosis: a geographically based study. 2. Predictive value of the early clinical course. Brain 1989;112 (Pt 6):1419-28. [MEDLINE: 90090007; EMBASE-1990024556]

\section{Yusuf 1985}

Yusuf S, Peto R, Lewis J, Collins R, Sleight P. Beta blockade during and after myocardial infarction: an overview of the randomised trials. Progress in Cardiovascular Diseases 1985;27(5):335-71. [MEDLINE: 85141015]

* Indicates the major publication for the study 
Durelli 1994

\begin{tabular}{ll}
\hline Methods & Randomised controlled trial. \\
Centrally randomization performed at Roche S.p.A., Milan, Italy \\
Intention to treat. \\
Double-blind; however, the occurence of side effects, mainly injection site reactions, raises doubts \\
about blindness of patients. \\
Treatment period 6 months. \\
Follow-up 6 months. \\
Withdrawn criteria: not reported. \\
Withdrawals 0. \\
Lost to follow-up 0 \\
20 patients: 9.0 MIU IFNA-2a 12, placebo 8. \\
Italy 1 Centre. \\
Sex: both. \\
Age: $18-57$ years. \\
Included: clinical definite relapsing-remitting MS (Poser 1983) of duration > 3 years; at least 2 exacerba- \\
tions in the 2 years before study entry, no exacerbations for 3 months before entry; EDSS = 6.0 or less; \\
normal blood, liver, and renal function. \\
Excluded: other severe illness; pregnancy; prior interferon or cytostatic drugs; corticotropin or corticos- \\
teroids in 3 months before entry. \\
Baseline characteristics: \\
55\% female \\
mean age (range): IFNA-2a 33 years (18-46), placebo 38 years (29-57) \\
mean EDSS (range): IFNA-2a 3.4 (1-6), placebo 2.8 (1.5-5) \\
mean disease duration (range): IFNA-2a 8.9 years (3-19), placebo 6.4 years (3-10).
\end{tabular}

Interventions

Rx: 9.0 MIU IFNA-2a (Roferon)

Placebo: human albumin and sodium chloride

IFNB or placebo self-admin. i.m. every other day for 6 months.

All patients received paracetamol $2 \mathrm{~h}$. before and 2 and $8 \mathrm{~h}$. after treatment.

Co-intervention: intravenous methylprednisolone tapered over 15 days, followed by oral prednisone

tapered over 15 days to treat exacerbations.

Outcomes

Primary outcomes: number of patients who continued to experience exacerbations and exacerbation rate during the first 6 months of treatment; exacerbation severity measured by the Neurological Rating Scale (NRS), median time to first exacerbation.

Other clinical outcomes: mean (without standard deviation) Expanded Disability Status Scale (EDSS) and NRS at 6 months.

Exacerbation defined as "acute or subacute objective deterioration of neurologic status attributable to MS, lasting at least $24 \mathrm{~h}$. in absence of fever and followed by complete or partial resolution (Poser, 1983).

Severity of exacerbation was defined as "change in the NRS ( 0 to $7=$ mild; 8 to $14=$ moderate; $>14=$ severe)".

Magnetic Resonance Imaging (MRI): number of patients who had active lesions at 6th month, mean number of active lesions per patient at 6 th month, total number of enlarging lesions and new lesions at 6th month.

Active lesion: defined.

Side effects and adverse events: described (method of data collection not reported).

Neutralizing antibodies: not mentioned.

$\begin{array}{ll}\text { Notes } & \text { Recruitment period not reported. } \\ & \text { Sponsored in part by Roche S.p.A., Milan, Italy. }\end{array}$

\section{Risk of bias}

Bias Authors' judgement Support for judgement

Allocation concealment? Low risk A-Adequate




Randomised controlled trial.
Central randomisation.
Intention to treat mentioned.
Double-blind; however, the occurrence of side effects, mainly injection site reactions, raises doubt as to
real blindness of patients.
Treatment 2 years.
Follow-up 2 years.
After 2 nd year all patients still in study given choice of continuing treatment, extending the treatment
period to 5 years for some patients. Therefore after 2 nd year the study was not blind. For this reason
this review considers only 2 years of follow-up.
Withdrawal: steady worsening of EDSS (> 1 point) for 6 months; > 3 courses of ACTH or steroid in 1 -
year period; non-compliance $>2$ consecutive weeks; moderate or severe drug toxicity re-occurring on
rechallenge.
Withdrawals and losses at 2 years = 68 patients:
1.6 MIU IFNB-1b = 20 patients ( 5 adverse events, 3 worsening, 2 prohibited drugs, 2 non-compliance or
losses to follow-up, 1 entry violation, 7 other reasons),
8.0 MIU IFNB-1b = 25 patients (10 adverse events, 9 worsening, 1 prohibited drugs, 2 non-compliance or
losses to follow-up, 1 entry violation, 2 other reasons),
placebo $=23$ patients (1adverse events, 5 worsening, 9 prohibited drugs, 2 non-compliance or losses to
follow-up, 1 entry violation, 5 other reasons).

Participants

372 patients: 1.6 MIU IFNB- $1 b=125,8.0$ MIU IFNB- $1 b=124$, placebo $=123$.

US and Canada 11 Centres.

Sex: both.

Age: $18-50$ years.

Included: clinically or laboratory-supported definite relapsing-remitting MS (Poser, 1983) of more than

1 year duration; at least 2 exacerbations in the 2 years before study entry; free of exacerbations for at

least 1 month before entry; EDSS $=5.5$ or less.

Excluded: use of ACTH or prednisone in the month before entry; prior treatment with azathioprine or cyclophosphamide.

Baseline characteristics:

$70 \%$ female

mean age: IFNB 1.6 MIU 35.3 years, IFNB 8 MIU 35.2 years, placebo 36.0 years

mean EDSS: IFNB 1.6 MIU 2.9, IFNB 8 MIU 3.0, placebo 2.8

mean disease duration: IFNB 1.6 MIU 4.7 years, IFNB 8 MIU 4.7 years, placebo 3.9 years.

Interventions

Rx 1: 1.6 MIU IFNB-1b (Betaseron or Betaferon)

$\mathrm{Rx}$ 2: 8.0 MIU IFNB-1b

Placebo: human albumin and dextrose

IFNB or placebo self-administered subcutaneously every other day for 2 years

Co-intervention: ACTH or prednisone for exacerbation

Outcomes

Primary outcomes: annual exacerbation rate and proportion of exacerbation-free patients over the 2 years.

Secondary clinical outcomes: number of patients who progressed at 2 years, median time to first exacerbation, exacerbation duration and severity, mean (and standard deviation) annual change in EDSS, median time to progression.

Exacerbation defined as "a new symptom or worsening of old symptom accompanied by new neurologic abnormality, lasting at least $24 \mathrm{~h}$. in absence of fever and preceded by stability or improvement for at least 30 days" (Schumacher, 1968).

Severity of exacerbation defined as change in the NRS ( 0 to $7=$ mild; 8 to $14=$ moderate; $>14=$ severe). Disease progression defined as "increase in EDSS of at least 1.0 point sustained over at least 3 month". MRI: annual mean and median \% change in total lesion area from baseline.

Proportion of active scans/patient and annual rate of active lesions/patient in a subgroup (14\%) who had scans every 6 weeks.

Active scan and new or enlarging lesion: defined.

Adverse events: criteria for monitoring and recording were not specified. 
IFNB MS Group 1993 (Continued)

Neutralizing antibodies: reported.

Notes Recruitment period: June 1988-May 1990.

Sponsored by Triton Biosciences, Inc., Alameda, CA and Berlex Laboratories Inc.

Withdrawals and losses to follow-up: conflicting figures in the articles and letters reporting trial.

Blindness: $80 \%$ patients in 8 MIU IFNB-1b arm, $51 \%$ in 1.6 MIU IFNB-1b arm and 30\% placebo correctly guessed treatment.

\section{Risk of bias}

Bias Authors' judgement Support for judgement

Allocation concealment? Unclear risk B-Unclear

Knobler 1993

\section{Methods}

Randomised controlled trial, 30 initially randomised; one more patient randomised to substitute one withdrawn at 14th day.

Allocation concealment: not reported.

Intention to treat not mentioned.

Double-blind; however, occurrence of side effects and crossing to different IFNB-1b dose after 6

months raise doubt as to true blindness of patients.

After 24 weeks all patients initially randomised to IFNB-1b crossed to 8.0 MIU.

Treatment 3 years.

Follow-up 3 years

After the 3rd year all patients still in the study given choice of continuing open label treatment, extend-

ing the treatment period to 6 years. Therefore after $3 r d$ year the study was not randomised. Therefore

this review considered 3 years of follow-up.

Withdrawals: steady worsening of EDSS ( $>1$ point) for 6 months; $>3$ courses of ACTH or steroid over 1-

year; non-compliance $>2$ consecutive weeks; persistence or recurrence of moderate or severe drug tox-

icity after rechallenge with half dose.

Withdrawals $=6$ patients: 0.8 MIU IFNB- $1 \mathrm{~b}=1$ prohibited treatment, 4.0 MIU IFNB- $1 \mathrm{~b}=2$ ( 1 prohibited

treatment, 1 non-compliance), 8.0 MIU IFNB-1b = 1 prohibited treatment, 16.0 MIU IFNB-1b = 0, placebo

$=1$ prohibited treatment. Unknown treatment for 1 for accidental un-blinding.

Losses to follow-up $=7$ patients (all self-terminated):

0.8 MIU IFNB- $1 \mathrm{~b}=1$

4.0 MIU IFNB- $1 b=1$

8.0 MIU IFNB- $1 b=1$

16 MIU IFNB-1b = 2

placebo $=2$

Participants

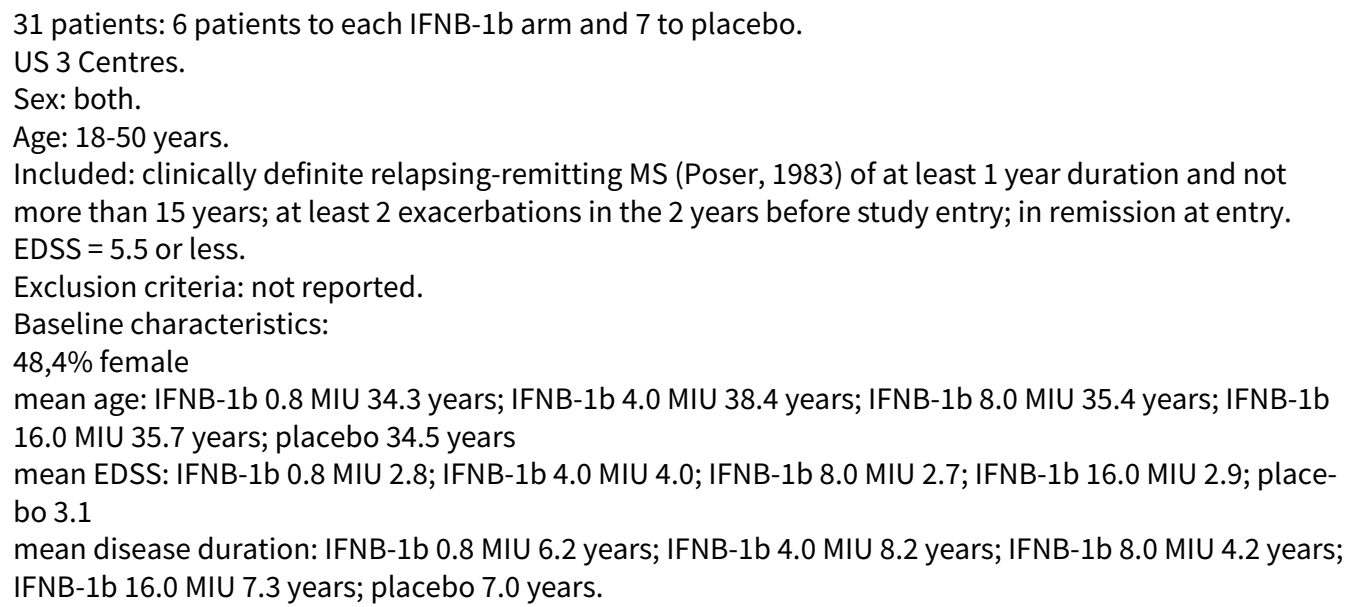


Knobler 1993 (Continued)

Interventions

Rx 1: 0.8 MIU IFNB-1b (Betaseron or Betaferon)

$\mathrm{Rx} 2:$ 4.0 MIU IFNB-1b

$\mathrm{R} \times$ 3: 8.0 MIU IFNB-1b

Rx 4: 16.0 MIU IFNB-1b

Placebo: human albumin.

IFNB or placebo self-administered subcutaneously 3 times weekly for 3 years.

Co-intervention: intravenous ACTH, methylprednisolone, or oral prednisone for exacerbations.

Primary outcomes: number of patients who contimued to experience exacerbations during the first
24 weeks, annual exacerbation rate, median time to first exacerbation and proportion of exacerba-
tion-free patients at 3 years.
Exacerbation was defined as "new symptom or worsening of an old symptom in absence of fever, as-
sociated with a new abnormality of at least 24 h. duration, which followed clinical stability or improve-
ment of at least 30 days duration" (Schumacher, 1968).
Adverse events: reported.
Neutralizing antibodies: reported.

Notes

Recruitment period: June-October 1986.

Sponsored by Triton Biosciences, Inc., Alameda, CA and Berlex Laboratories Inc.

Poor description of results.

\section{Risk of bias}

\begin{tabular}{lll}
\hline Bias & Authors' judgement & Support for judgement \\
\hline Allocation concealment? & Unclear risk & B - Unclear \\
\hline
\end{tabular}

Myhr 1999

Randomised controlled trial.
Allocation concealment: not reported.
Intention to treat mentioned.
Double-blind; however, occurrence of side effects, mainly injection site reactions, raises doubts as true
blindness of patients.
Treatment $=6$ months.
Follow-up $=12$ months.
Reason for withdrawal: worsening of EDSS; $>2$ courses with corticosteroids; non-compliance $>3$ con-
secutive doses or total of 15 doses during study; persistent moderate to severe side effects of IFNA-2a.
Withdrawals $=6$ patients: 4.5 MIU IFNA-2a = 3 (adverse effects), 9.0 MIU IFNA-2a = 3 (1 non-compliance;

2 adverse effects) and placebo $=0$.
Losses to follow-up $=4$ patients: 4.5 IFNA-2a = 1 (exacerbation), 9.0 MIU IFNA-2a $=2$ (exacerbation) and
placebo $=1$ (patient decision).

Participants

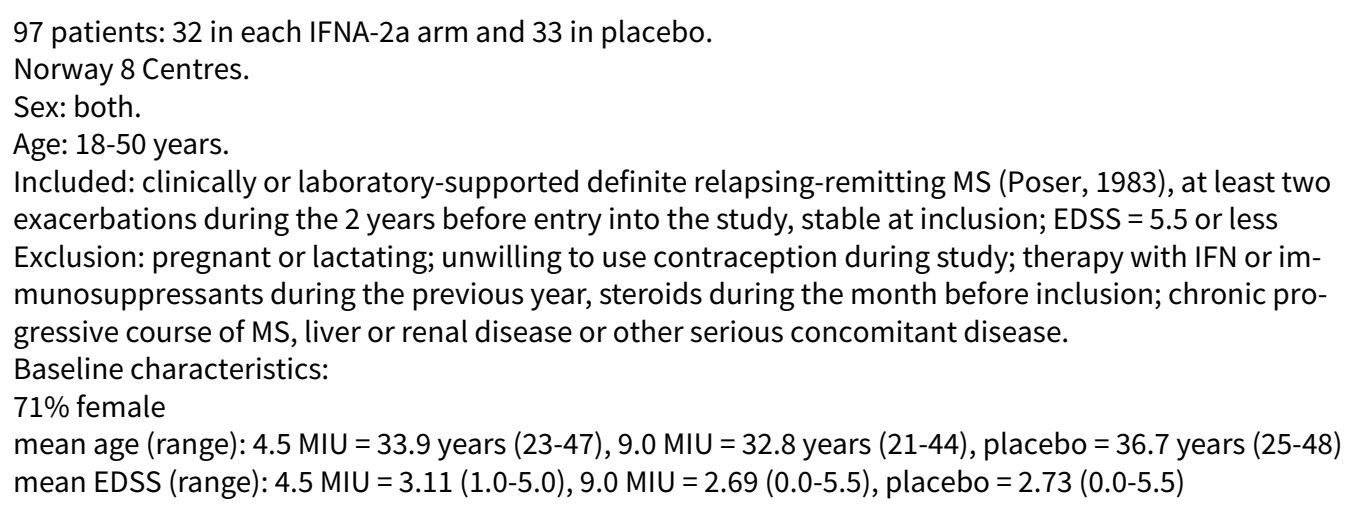


Myhr 1999 (Continued)

mean disease duration (range): $4.5 \mathrm{MIU}=7.6$ years $(1-25), 9.0 \mathrm{MIU}=7.5$ years $(1-18)$, placebo $=5.5$ years (1-19).

Interventions

Rx 1: 4.5 MIU IFNA-2a (Roferon)

Rx 2: 9.0 MIU IFNA-2a

Placebo: constituents not reported.

IFNA or placebo administered by study physician subcutaneously 3 times weekly for 6 months.

Co-intervention: methylprednisolone intravenous for 3 days followed by prednisolone tapered over 14

days for exacerbations.

Outcomes

Primary MRI outcomes: mean (without standard deviation) and median of new lesions per patient at 6 months and 1 year. Number of patients who had new active lesions. Mean and median of total number of lesions per patient.

New lesion: not defined.

Secondary clinical outcomes: annual exacerbation rate, exacerbation-free patients, mean (without standard deviation) and median change in EDSS, quality of life (SF-36 Health Survey and General Health Questionnaire 20). All outcomes were at 6 months and 1 year.

Exacerbation was defined as "new symptom or worsening of an old symptom in absence of fever, associated with new abnormality of at least $24 \mathrm{~h}$. duration, which followed clinical stability or improvement of at least 30 days duration" (Schumacher, 1968).

Severity of exacerbation defined as change in the NRS ( 0 to $7=$ mild; 8 to $14=$ moderate; $>14=$ severe). Adverse events: criteria for monitoring and recording were reported (WHO criteria for reporting results of cancer treatment).

Neutralizing antibodies: reported.

Notes When recruited: not specified.

Sponsored by Roche Norge and Nycomed Imaging, Oslo, Norway.

\section{Risk of bias}

\begin{tabular}{lll}
\hline Bias & Authors' judgement & Support for judgement \\
\hline Allocation concealment? & Unclear risk & B - Unclear \\
\hline
\end{tabular}

Polman 2003

Randomised, double-blind controlled trial.
Allocation concealment: not reported.
Intention to treat mentioned.
Treatment $=6$ months.
Fllow up: not specified.
Treatment prematurely discontinued: 0.06 MIU =2 (adverse events); 6 MIU =3 ( 1 withdrawal of consent,
1 adverse events, 1 other); placebo $=3$ ( 1 withdrawal of consent, 1 adverse events, 1 other)

Participants

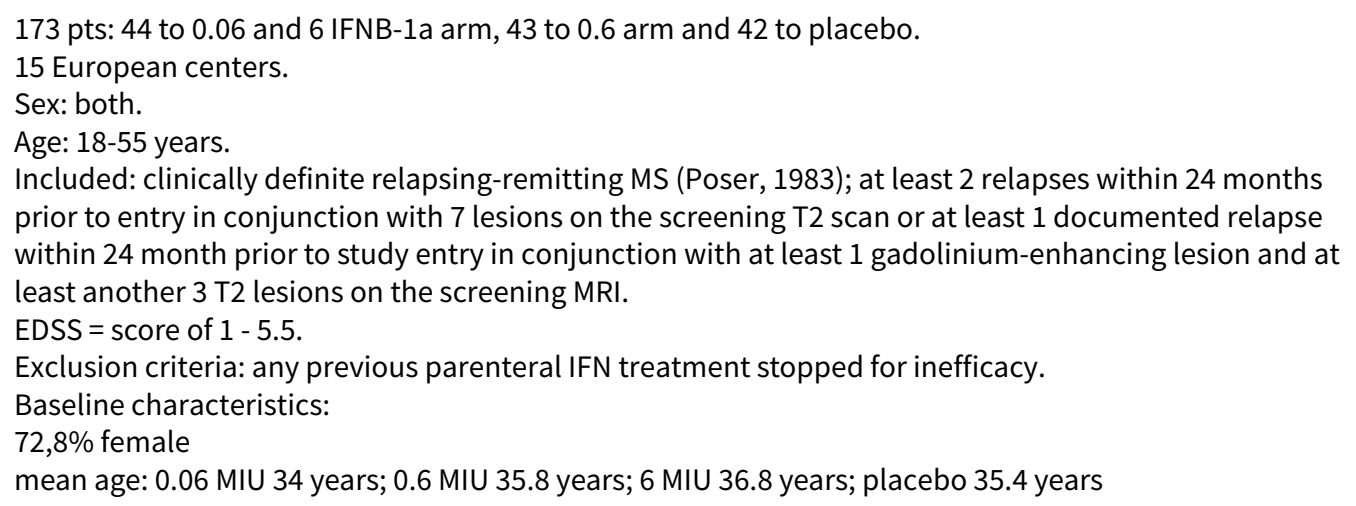


Polman 2003 (Continued)

years since onset of MS (median): 0.06 MIU 5 years; 0.6 MIU 5 years; 6 MIU 5 years; placebo 5.5 years

Rx 1: 0.06 MIU IFNB-1a
Rx 2: 0.6 MIU IFNB-1a
Rx 2: 6 MIU IFNB-1a
Placebo
IFNB or placebo self-administered every day via oral route.
Pts were instructed to ingest the drug in a fasting state 30 min before breakfast. They were to retain the
solution in the mouth for 2 min before swallowing.
Primary: cumulative number of newly active lesions over 6 months as seen on monthly brain MRI scan.
Newly active lesions display one of the following features: new gadolinium enhancement on T1-weight-
ed images, new on T2-weighted images but non-enhancing on T1-weighted images, new enlargement
on T2-weighted images but non-enhancing on T1-weighted images.
Secondary: cumulative number of newly active lesions over 1, 2, 3, 4 and 5 months of treatment; cumu-
lative number of newly active lesions on monthly scans over months 4 to $6 ;$ number of newly active le-
sions at each individual monthly time point; volume of gadolinium-enhancing lesions at each individ-
ual monthly time point; volume of hypertense lesions seen on T2-weighted scans after 3 and 6 months
of treatment; scan activity at each monthly visit (ie. the proportion of active scans per pts); patients ac-
tivity (ie. the proportion of pts with at least 1 post-baseline active scan).

$\begin{array}{ll}\text { Notes } & \text { When recruited: not specified. } \\ \text { Sponsored by Schering AG. }\end{array}$

Sponsored by Schering AG.

\title{
Risk of bias
}

\begin{tabular}{lll}
\hline Bias & Authors' judgement & Support for judgement \\
\hline Allocation concealment? & Unclear risk & B - Unclear \\
\hline
\end{tabular}

\section{The MSCRG 1996}

\section{Methods}

\author{
Randomised controlled trial. \\ Randomisation at statistical centre of Buffalo General Hospital, one of the participating centres (biased \\ coin). \\ Allocation concealment: schedule sent to each clinical centre, included patients were sequentially as- \\ signed the next ID number from the schedule. \\ Intention to treat mentioned. \\ Double-blind; however, occurrence of side effects, mainly injection site reactions, raises doubts as true \\ blindness of patients. \\ Treatment $=104$ weeks. \\ Follow-up $=2$ years. \\ Reasons for withdrawal : pregnancy, encephalopathy, increased levels of hepatic enzymes and creati- \\ nine, white blood count $<2300$, platelet count $<80.000$, heart failure, adverse events, non-compliance, \\ protocol violation. \\ Withdrawals $=23$ patients: IFNB-1a $=14$ (non-compliance), placebo $=9$ (non-compliance). \\ Losses to follow-up: 5 patients (reasons and treatment group not reported). \\ 129 patients did not reach 2 years of follow-up because study ended prematurely.
}

\section{Participants}

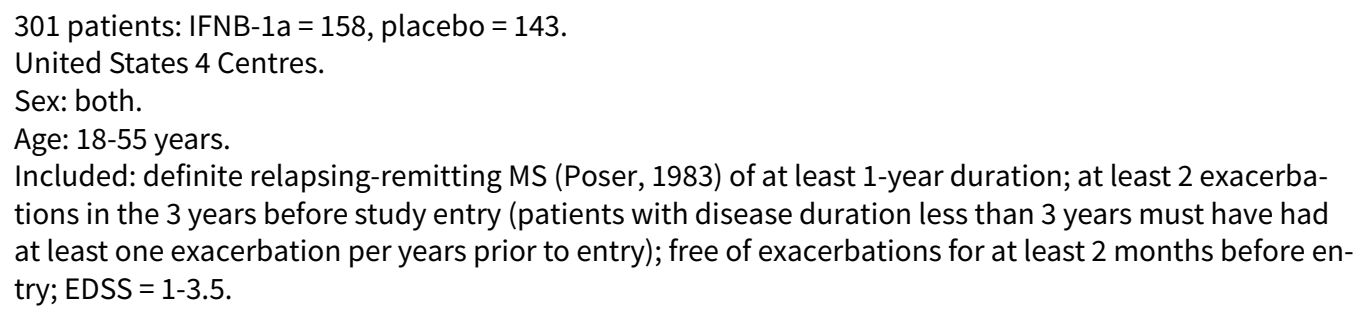


The MSCRG 1996 (Continued)

Exclusion: prior therapy with immunosuppressants or interferon; ACTH or corticosteroids in 2 months before entry; concurrent infection or other serious disease; chronic progressive MS; pregnant or lactating; unwilling to use contraception during study.

Baseline characteristics:

$73,5 \%$ female

mean age (range): IFNB-1a $=36.7$ years $(18-55)$, placebo $=36.9$ years $(16-54)$

mean EDSS (range): IFNB-1a $=2.4(1.0-3.5)$, placebo $=2.3(1.0-3.5)$

mean disease duration (range): IFNB- $1 a=6.6$ years $(1.0-30.7)$, placebo $=6.4$ years $(1.0-31.0)$.

Interventions Rx: 6.0 MIU IFNB-1a (Avonex)

Placebo: human albumin.

IFNB-1a or placebo intramuscular given weekly for 104 weeks by study nurses or local health professionals under supervision of study personnel.

Co-intervention: intramuscular ACTH or intravenous methylprednisolone followed by tapered oral prednisone for exacerbations.

Outcomes

Primary outcome: mean time to disability progression (EDSS-measured).

Other clinical outcomes: median time to first exacerbation, proportion of exacerbation-free patients at

2 years, number of relapses per patient at 1 and 2 years, annual exacerbation rate, mean (without standard deviation) change in EDSS.

Sustained worsening in disability defined as "deterioration from baseline 1.0 points on EDSS persisting at least 6 months".

Exacerbation defined as "new symptom or worsening of an old symptom of at least $48 \mathrm{~h}$., which followed clinical stability or improvement of at least 30 days duration" (Jacobs, 1995).

MRI: number of patients who had active lesions at 1st and 2nd years. Mean (standard error) number and volume of active lesions per patient. Median \% change of total lesion volume from baseline. New lesion: defined.

Other clinical outcomes: time to first worsening in visual function and time to beginning of sustained visual function progression (EDSS-measured); time to beginning of sustained progression of disability in upper and lower extremity function (EDSS-measured).

Other measures: neuropsychological (MSCRG battery), emotional status (defined), functional assessment (defined), quality of life (Sickness Impact Profile).

Adverse events: criteria for monitoring and recording clearly described (according to Food and Drug Administration, HHS 21 CFR, Chapters 1,312.32, part c, 4/1/90).

Neutralizing antibodies: reported.

Notes

Recruitment period: November 1990 - early 1993

Supported by National Institutes of Health, National Institute of Neurological Disorders and Stroke (NINDS) and Biogen, Inc, Cambridge, MA

Withdrawals and losses to follow-up: poorly described.

\section{Risk of bias}

Bias Authors' judgement Support for judgement

Allocation concealment? Unclear risk B - Unclear

\section{The OWIMS 1999}

Methods

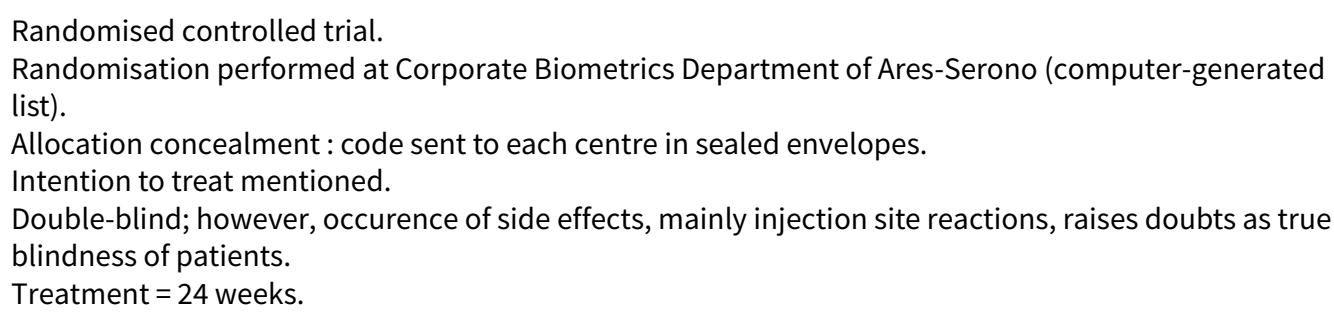


The OWIMS 1999 (Continued)

Follow-up $=48$ weeks.

Withdrawal criteria: not described.

Withdrawals $=10$ patients: $6.0 \mathrm{MIU}=2$ ( 1 allergy to Gadolinium, 1 adverse events), $12.0 \mathrm{MIU}=8$ ( 5 ad-

verse events, 1 protocol deviation, 1 worsening, 1 pregnancy), placebo $=0$.

Losses to follow-up = 14 patients: $6.0 \mathrm{MIU}=6,12.0 \mathrm{MIU}=5$, placebo $=3$.

Participants
Canada, Netherlands, Italy, Israel and France 11 Centres.
Sex: both.
Age: $18-50$ years.
Included: clinically or laboratory-supported definite relapsing-remitting MS (Poser, 1983) of at least 1
year duration; at least one exacerbation in the 2 years; free of exacerbations for at least 8 weeks before
entry; EDSS = 0-5.0; at least 3 lesions consistent with MS were required on a screening magnetic reso-
nance.
Exclusion: prior interferon, cyclophosphamide, or lymphoid irradiation treatment; use of any immuno-
suppressive or experimental therapies in the preceding 12 months before entry; corticosteroids in 8
weeks before entry; pregnancy; lactation; other severe medical or psychiatric disease.
Baseline characteristics:
73\% female
mean age: IFNB-1a 6 MIU = 35.4 years; IFNB-1a 12 MIU = 35.5 years; placebo = 34.9 years
mean EDSS: IFNB-1a 6 MIU = 2.7; IFNB-1a 12 MIU = 2.6; placebo = 2.6
mean disease duration: IFNB-1a 6 MIU = 6.9 years; IFNB-1a 12 MIU = 6.7 years; placebo = 6.3 years.

Interventions Rx 1: 6.0 MIU IFNB-1a (Rebif)

Rx 2: 12.0 MIU IFNB-1a

Placebo: human albumin and mannitol.

IFNA or placebo administered subcutaneously weekly for 24 weeks, by study treating physician.

Co-intervention: methylprednisolone intravenous for 3 consecutive days for exacerbations.

Primary MRI outcomes (at 24 weeks): mean active lesion rate/ patient/scan espressed as median for
each group.
Secondary MRI outcomes (at 48 weeks): median of active lesions and \% change in total lesion area at
monthly scans.
Active lesion and change in total lesion area: defined.
Clinical outcomes: number of exacerbations/patient, exacerbation severity (EDSS and NRS-mea-
sured), median time to first exacerbation, proportion of exacerbation-free patients, mean steroid treat-
ments/patient and hospitalisations related to MS.
Exacerbation defined as "new symptom or worsening of old symptom in absence of fever, associated
with new abnormality of at least 24 h. duration, which followed clinical stability or improvement of at
least 30 days duration" (Schumacher, 1968).
Adverse effects: reported.
Neutralizing antibodies: reported.

Notes

Recruited: March-November 1995

Sponsored by Ares-Serono International SA, Geneva, Switzerland.

\section{Risk of bias}

Bias Authors' judgement Support for judgement

Allocation concealment? Low risk A-Adequate

\section{The PRISMS 1998}

$\begin{array}{ll}\text { Methods } & \text { Randomised controlled trial. } \\ \text { Randomisation at Corporate Biometrics Department of Ares-Serono (computer-generated list, strati- } \\ \text { fied by centre, equal allocation of the treatment groups by a block size of } 6 \text { ). }\end{array}$


The PRISMS 1998 (Continued)

Intention to treat mentioned.

Double-blind; however, occurence of side effects, mainly injection site reactions, raises doubts as to

true blindness of patients.

Treatment period $=2$ years.

Follow-up $=2$ years.

Reason for withdrawal: WHO grade IV toxic effects; protocol violations; non-compliance.

Withdrawals $=32$ patients: $6.0 \mathrm{MIU}=12$ (1 worsening, 1 death, 6 adverse events, 2 unknown, 2 preg-

nant), $12.0 \mathrm{MIU}=13$ ( 9 adverse events, 3 pregnant, 1 protocol violation), placebo $=7$ ( 3 worsening, 2 ad-

verse events, 1 death, 1 pregnant).

Losses to follow-up = 26 patients: $6.0 \mathrm{MIU}=10 ; 12.0 \mathrm{MIU}=6$; placebo $=10$.

Participants
Canada, Germany, Netherlands, Australia, Sweden, Finland, Belgium, United Kingdom and Switzerland
22 Centres.
Sex: both.
Included: clinically or laboratory-supported definite relapsing-remitting MS (Poser, 1983) of at least 1
year duration; at least 2 exacerbations in the 2 years before entry; EDSS $=0-5.0$.
Exclusion: prior interferon, lymphoid irradiation, cyclophosphamide, immunomodulatory or immuno-
suppressive treatment in the preceding 12 months.
Baseline characteristics:
69\% female
median age: IFNB-1a 6 MIU = 34.8 years, IFNB-1a 12 MIU = 35.6, placebo 34.6
mean EDSS: IFNB-1a 6 MIU = 2.5, IFNB-1a 12 MIU = 2.5, placebo = 2.4
median disease duration: IFNB-1a 6 MIU $=5.4$ years, IFNB-1a 12 MIU = 6.4 years, placebo $=4.3$ years.

Interventions $\quad$ Rx 1: 6.0 MIU IFNB-1a (Rebif)

Rx 2: 12.0 MIU IFNB-1a

Placebo: constituents not reported.

IFNB or placebo administered subcutaneously 3 times weekly for two years, by treating study physician.

Co-intervention: paracetamol for influenza-like side effects and intravenous methylprednisolone for 3 consecutive days for exacerbations.

Outcomes Primary outcomes: number of exacerbations/patient, exacerbation severity (NRS or the activities of daily living scale-measured).

Other outcomes: number of patients who progressed at 2 years, median times to first and second exacerbation, proportion of exacerbation-free patients, first quartile time to progression, mean (and standard deviation) change of EDSS from baseline.

Exacerbation defined according to Schumacher (1968).

Progression in disability defined as "increase in EDSS of at least 1.0 point sustained over at least 3 months, ambulation index (Hauser 1983), arm-function index (Barnes 1997), need for steroid therapy and hospital admission".

Severity of exacerbations defined as "change in NRS ( 0 to $7=$ mild; 8 to $14=$ moderate; $>14=$ severe) or the activities of daily living scale (mild: no effect; moderate: significant effect; severe: hospital admission)".

MRI: annual change of total lesion area.

Total lesion area: not defined.

Adverse events: reported.

Neutralizing antibodies: reported.

Notes

Recruited: May 1994-February 1995

Supported by: Ares-Serono International SA, Geneva, Switzerland.

\section{Risk of bias}

Bias Authors' judgement Support for judgement

Allocation concealment? Low risk A-Adequate


EDSS: Expanded Disability Status Scale

IFNA-2a: interferon alfa-2a

IFNB-1a: interferon beta- 1 a

IFNB-1b: interferon beta- $1 b$

Interferon beta- $1 \mathrm{~b}$ (Betaseron, Betaferon) [Drug company: Berlex Laboratories in North America, Schering AG in Europe and other countries of the world]

Interferon beta- 1a (Avonex) [Drug company: Biogen, Inc.]

Interferon beta- 1a (Rebif) [Drug company: Ares Serono International SA ]

Interferon alfa- 2a (Roferon) [Drug company: F. Hoffmann-La Roche Ltd. ]

MIU: million international units

MRI: magnetic resonance imaging

Rx: treatment

Characteristics of excluded studies [ordered by study ID]

\begin{tabular}{|c|c|}
\hline Study & Reason for exclusion \\
\hline AUSTIMS 1989 & The patients were treated with natural interferon-alfa \\
\hline Granger 2003 & Secondary analysis of the MSCRG 1996 \\
\hline Herndon 1999 & Open-label study (safety extension study) \\
\hline Hirsch 1986 & Immunological outcomes only \\
\hline Jacobs 2000 & Patients were included during a first exacerbation, prior to a definite diagnosis of multiple sclerosis \\
\hline Knobler 1984 & The patients were treated with natural interferon-alfa \\
\hline Milanese 1990 & The patients were treated with natural interferon-alfa \\
\hline Pozzilli 1997 & A dose comparison study of interferon beta-1a without a placebo group \\
\hline Rudge 1995 & $\begin{array}{l}\text { This study included progressive patients and only } 2 \text { patients with relapsing-remitting multiple scle- } \\
\text { rosis }\end{array}$ \\
\hline Rudick 1998 & Open-label study (safety extension study) \\
\hline Schwartz 1997 & Neither blinding criteria nor clinical outcomes were described \\
\hline Simon 1999 & The authors reported data only relating to the placebo group of a study on interferon beta-1a \\
\hline
\end{tabular}

DATA AND ANALYSES

Comparison 1. interferon versus placebo: primary outcomes

\begin{tabular}{llllll}
\hline Outcome or subgroup title & $\begin{array}{l}\text { No. of } \\
\text { studies }\end{array}$ & $\begin{array}{l}\text { No. of } \\
\text { partici- } \\
\text { pants }\end{array}$ & Statistical method & Effect size \\
\hline $\begin{array}{l}1 \text { Patients with at least one exacerbation } \\
\text { until } 1 \mathrm{yr}\end{array}$ & 5 & 667 & Risk Ratio (M-H, Random, 95\% Cl) & $0.73[0.55,0.97]$ \\
\hline
\end{tabular}




\begin{tabular}{|c|c|c|c|c|}
\hline Outcome or subgroup title & $\begin{array}{l}\text { No. of } \\
\text { studies }\end{array}$ & $\begin{array}{l}\text { No. of } \\
\text { partici- } \\
\text { pants }\end{array}$ & Statistical method & Effect size \\
\hline $\begin{array}{l}2 \text { Patients with at least one exacerbation } \\
\text { until } 1 \text { year: subgroup analysis }\end{array}$ & 5 & & Risk Ratio (M-H, Random, 95\% Cl) & Subtotals only \\
\hline 2.1 duration of treatment: 6 months & 3 & 283 & Risk Ratio (M-H, Random, 95\% Cl) & $0.65[0.33,1.29]$ \\
\hline 2.2 duration of treatment: 12 months & 2 & 384 & Risk Ratio (M-H, Random, 95\% Cl) & $0.52[0.14,1.92]$ \\
\hline $\begin{array}{l}3 \text { Patients with at least one exacerbation at } \\
2 \text { yrs }\end{array}$ & 3 & 919 & Risk Ratio (M-H, Fixed, 95\% Cl) & $0.80[0.73,0.88]$ \\
\hline $\begin{array}{l}4 \text { Patients with at least one exacerbation at } \\
2 \text { yrs (best scenario) }\end{array}$ & 3 & 919 & Risk Ratio (M-H, Random, 95\% Cl) & $0.62[0.44,0.87]$ \\
\hline $\begin{array}{l}5 \text { Patients with at least one exacerbation at } \\
2 \text { yrs (worst scenario) }\end{array}$ & 3 & 919 & Risk Ratio (M-H, Random, 95\% Cl) & $1.11[0.73,1.68]$ \\
\hline 6 Patients who progressed at $2 \mathrm{yrs}$ & 3 & 919 & Risk Ratio (M-H, Fixed, 95\% Cl) & $0.69[0.55,0.87]$ \\
\hline $\begin{array}{l}7 \text { Patients who progressed at } 2 \text { yrs (best } \\
\text { scenario) }\end{array}$ & 3 & 919 & Risk Ratio (M-H, Fixed, 95\% Cl) & $0.43[0.35,0.53]$ \\
\hline $\begin{array}{l}8 \text { Patients who progressed at } 2 \text { yrs (worst } \\
\text { scenario) }\end{array}$ & 3 & 919 & Risk Ratio (M-H, Random, 95\% Cl) & $1.31[0.60,2.89]$ \\
\hline 9 Mean change in disability (EDSS) at 2 yrs & 2 & 618 & Mean Difference (IV, Fixed, 95\% CI) & $-0.25[-0.46,-0.05]$ \\
\hline
\end{tabular}

Analysis 1.1. Comparison 1 interferon versus placebo: primary outcomes, Outcome 1 Patients with at least one exacerbation until 1 yr.

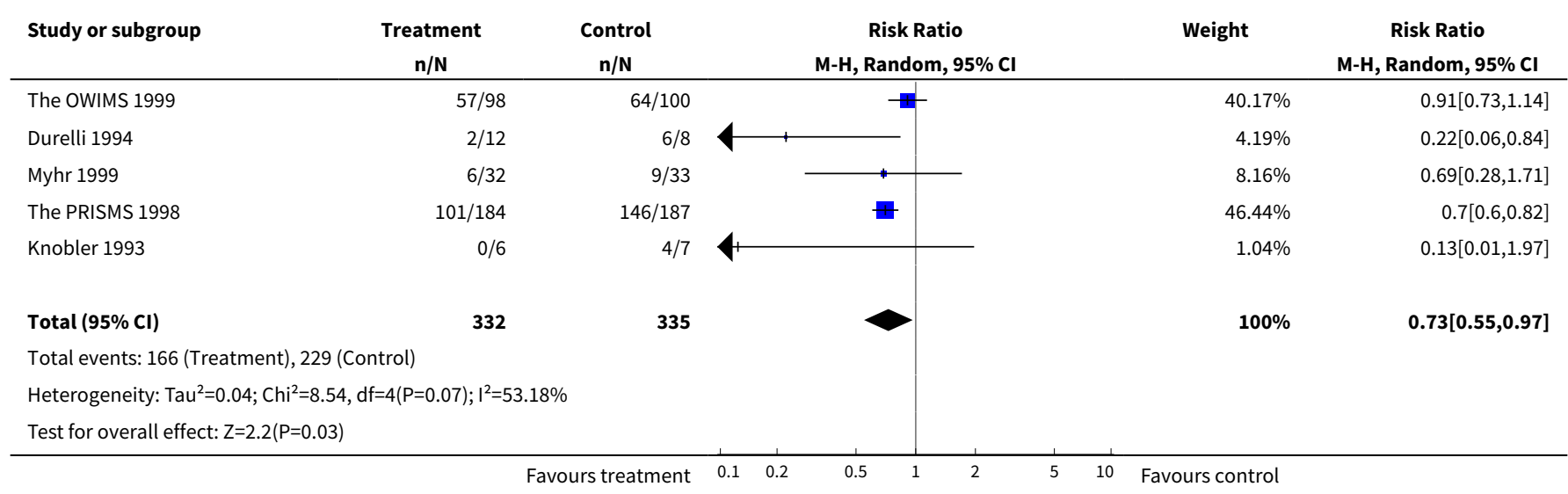


Analysis 1.2. Comparison 1 interferon versus placebo: primary outcomes, Outcome 2 Patients with at least one exacerbation until 1 year: subgroup analysis.

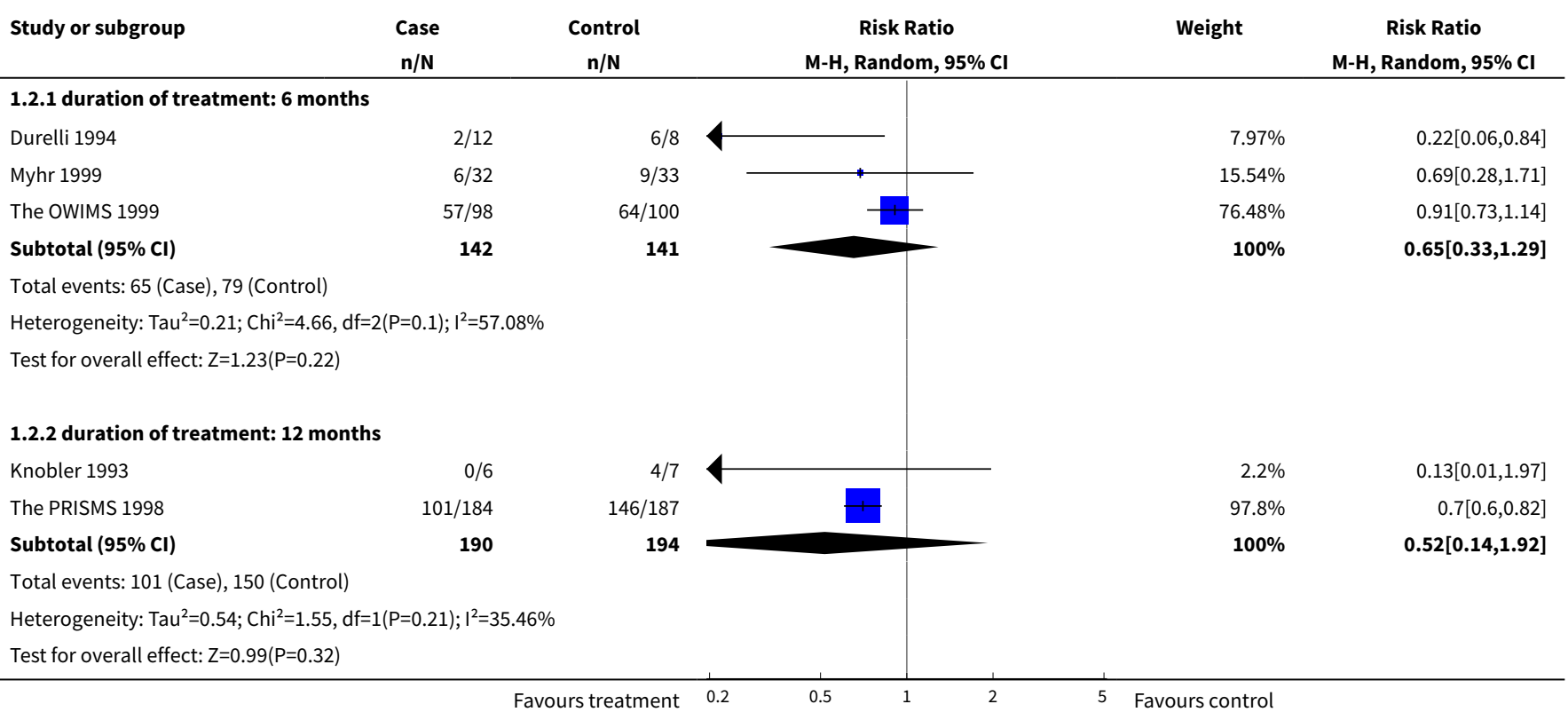

Analysis 1.3. Comparison 1 interferon versus placebo: primary outcomes, Outcome 3 Patients with at least one exacerbation at 2 yrs.

\begin{tabular}{|c|c|c|c|c|c|}
\hline Study or subgroup & $\begin{array}{c}\text { Treatment } \\
\mathrm{n} / \mathrm{N} \\
\end{array}$ & $\begin{array}{c}\text { Control } \\
\mathrm{n} / \mathrm{N}\end{array}$ & $\begin{array}{c}\text { Risk Ratio } \\
\text { M-H, Fixed, 95\% Cl }\end{array}$ & Weight & $\begin{array}{c}\text { Risk Ratio } \\
\text { M-H, Fixed, 95\% Cl }\end{array}$ \\
\hline IFNB MS Group 1993 & $79 / 124$ & $94 / 123$ & - & $29.74 \%$ & $0.83[0.71,0.98]$ \\
\hline The MSCRG 1996 & $53 / 158$ & $64 / 143$ & *- & $21.18 \%$ & $0.75[0.56,1]$ \\
\hline The PRISMS 1998 & $125 / 184$ & $157 / 187$ & $\mathbf{H}$ & $49.08 \%$ & $0.81[0.72,0.91]$ \\
\hline Total $(95 \% \mathrm{Cl})$ & 466 & 453 & 1 & $100 \%$ & $0.8[0.73,0.88]$ \\
\hline \multicolumn{6}{|c|}{ Heterogeneity: $\operatorname{Tau}^{2}=0 ; \mathrm{Chi}^{2}=0.43, \mathrm{df}=2(\mathrm{P}=0.81) ; \mathrm{I}^{2}=0 \%$} \\
\hline Test for overall effect & & & & & \\
\hline
\end{tabular}

Analysis 1.4. Comparison 1 interferon versus placebo: primary outcomes, Outcome 4 Patients with at least one exacerbation at 2 yrs (best scenario).

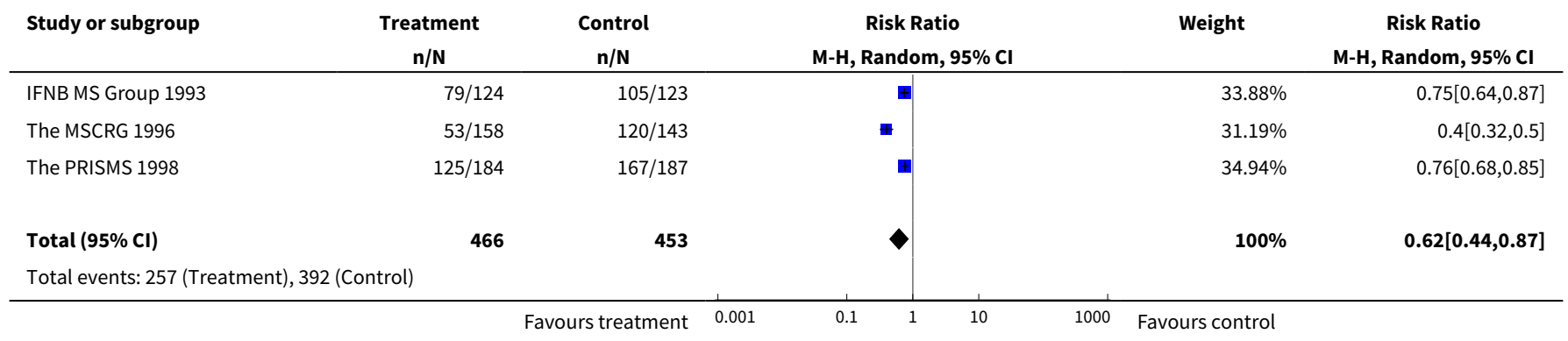




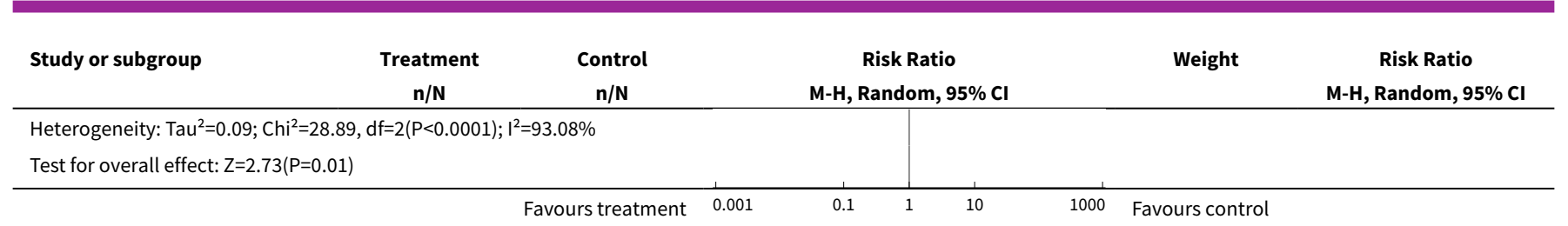

Analysis 1.5. Comparison 1 interferon versus placebo: primary outcomes, Outcome 5 Patients with at least one exacerbation at 2 yrs (worst scenario).

\begin{tabular}{|c|c|c|c|c|c|}
\hline Study or subgroup & $\begin{array}{c}\text { Treatment } \\
\mathrm{n} / \mathrm{N} \\
\end{array}$ & $\begin{array}{c}\text { Control } \\
\mathrm{n} / \mathrm{N}\end{array}$ & $\begin{array}{c}\text { Risk Ratio } \\
\text { M-H, Random, 95\% Cl }\end{array}$ & Weight & $\begin{array}{c}\text { Risk Ratio } \\
\text { M-H, Random, } 95 \% \text { CI } \\
\end{array}$ \\
\hline IFNB MS Group 1993 & $88 / 124$ & $94 / 123$ & 电 & $33.48 \%$ & $0.93[0.8,1.08]$ \\
\hline The MSCRG 1996 & $126 / 158$ & $64 / 143$ & = & $32.4 \%$ & $1.78[1.46,2.17]$ \\
\hline The PRISMS 1998 & $130 / 184$ & $157 / 187$ & 田 & $34.12 \%$ & $0.84[0.75,0.94]$ \\
\hline Total $(95 \% \mathrm{Cl})$ & 466 & 453 & & $100 \%$ & $1.11[0.73,1.68]$ \\
\hline \multicolumn{6}{|c|}{ Heterogeneity: $\operatorname{Tau}^{2}=0.13 ; \mathrm{Chi}^{2}=46.15, \mathrm{df}=2(\mathrm{P}<0.0001) ; \mathrm{I}^{2}=95.67 \%$} \\
\hline Test for overall effect & & & & & \\
\hline
\end{tabular}

Analysis 1.6. Comparison 1 interferon versus placebo: primary outcomes, Outcome 6 Patients who progressed at $2 \mathrm{yrs}$.

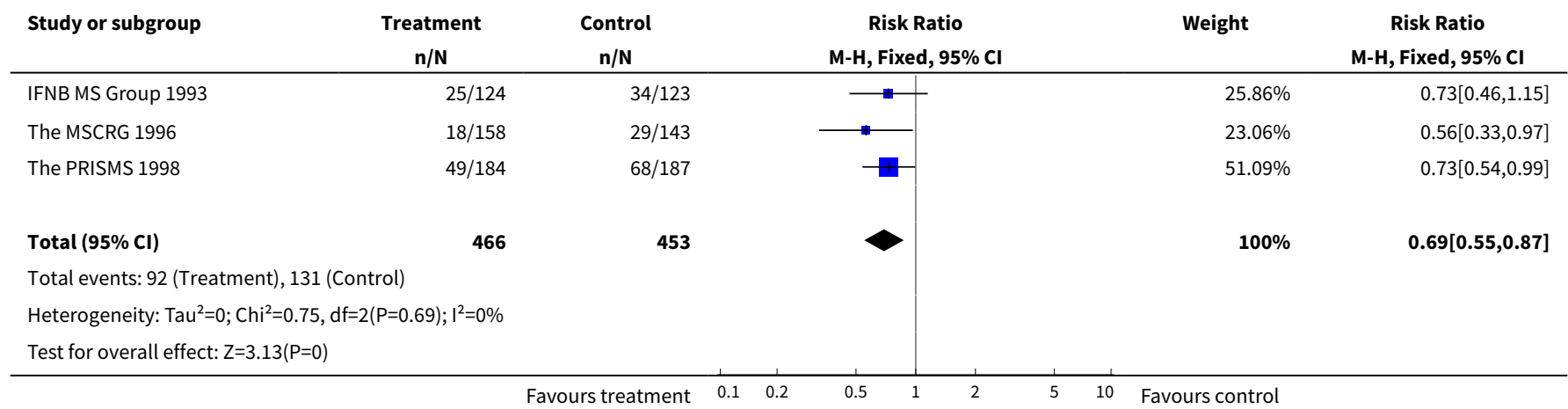

Analysis 1.7. Comparison 1 interferon versus placebo: primary outcomes, Outcome 7 Patients who progressed at 2 yrs (best scenario).

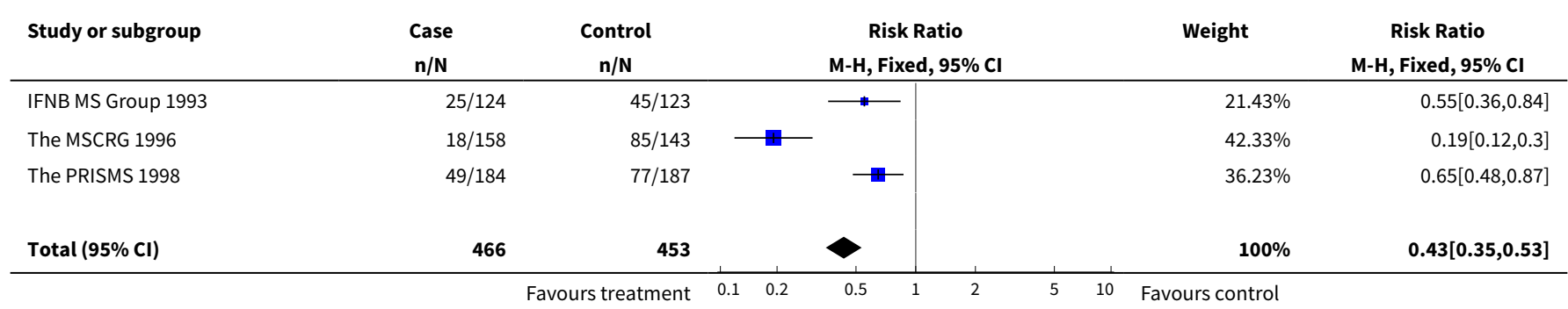




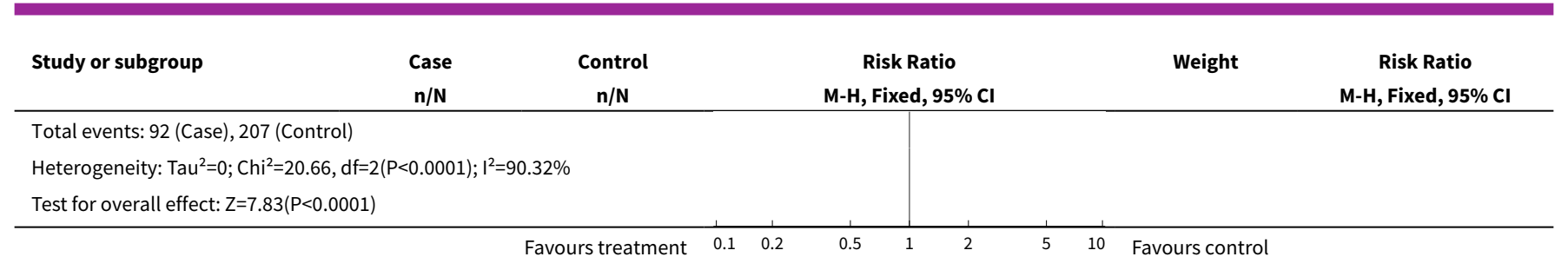

Analysis 1.8. Comparison 1 interferon versus placebo: primary outcomes, Outcome 8 Patients who progressed at 2 yrs (worst scenario).

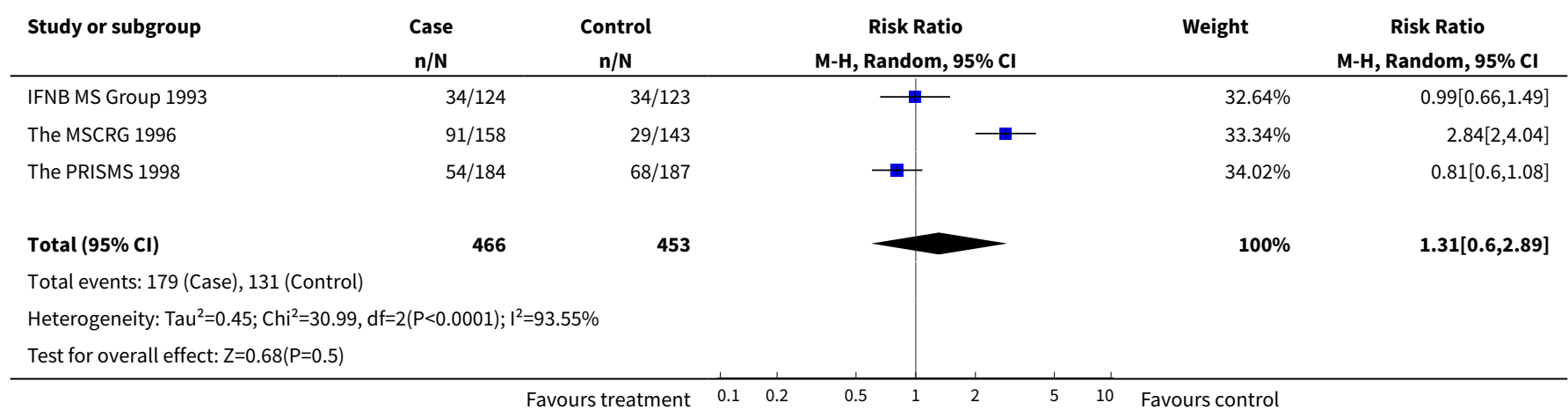

Analysis 1.9. Comparison 1 interferon versus placebo: primary outcomes, Outcome 9 Mean change in disability (EDSS) at 2 yrs.

\begin{tabular}{|c|c|c|c|c|c|c|c|}
\hline \multirow[t]{2}{*}{ Study or subgroup } & \multicolumn{2}{|c|}{ Treatment } & \multicolumn{2}{|c|}{ Control } & \multirow{2}{*}{$\begin{array}{c}\text { Mean Difference } \\
\text { Fixed, } 95 \% \mathrm{Cl}\end{array}$} & \multirow[t]{2}{*}{ Weight } & \multirow{2}{*}{$\begin{array}{c}\text { Mean Difference } \\
\text { Fixed, } 95 \% \mathrm{Cl}\end{array}$} \\
\hline & $\mathbf{N}$ & Mean(SD) & $\mathbf{N}$ & Mean(SD) & & & \\
\hline The PRISMS 1998 & 184 & $0.2(1.1)$ & 187 & $0.5(1.3)$ & + & $68.9 \%$ & $-0.24[-0.48,0]$ \\
\hline IFNB MS Group 1993 & 124 & $-0.1(1.4)$ & 123 & $0.2(1.5)$ & $=$ & $31.1 \%$ & $-0.28[-0.64,0.08]$ \\
\hline 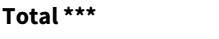 & 308 & & 310 & & 1 & $100 \%$ & $-0.25[-0.46,-0.05]$ \\
\hline \multicolumn{8}{|c|}{ Heterogeneity: $\operatorname{Tau}^{2}=0 ; \mathrm{Chi}^{2}=0.03, \mathrm{df}=1(\mathrm{P}=0.86) ; \mathrm{I}^{2}=0 \%$} \\
\hline \multicolumn{3}{|c|}{ Test for overall effect: $Z=2.43(P=0.01)$} & & & & & \\
\hline
\end{tabular}

\section{Comparison 2. Interferon versus placebo: secondary outcomes}

\begin{tabular}{llllll}
\hline Outcome or subgroup title & $\begin{array}{l}\text { No. of } \\
\text { studies }\end{array}$ & $\begin{array}{l}\text { No. of } \\
\text { partici- } \\
\text { pants }\end{array}$ & Statistical method & Effect size \\
\hline $\begin{array}{l}1 \text { Patients who required steroid treatment until } \\
\text { first year }\end{array}$ & 2 & 85 & Risk Ratio (M-H, Random, 95\% Cl) & $0.52[0.04,7.31]$ \\
\hline $\begin{array}{l}2 \text { Patients who required steroid treatment until } \\
\text { 2 years }\end{array}$ & 1 & 371 & Risk Ratio (M-H, Fixed, 95\% Cl) & $0.70[0.56,0.87]$ \\
\hline
\end{tabular}




\begin{tabular}{llllll}
\hline Outcome or subgroup title & $\begin{array}{l}\text { No. of } \\
\text { studies }\end{array}$ & $\begin{array}{l}\text { No. of } \\
\text { partici- } \\
\text { pants }\end{array}$ & Statistical method & Effect size \\
\hline $\begin{array}{l}\text { 3 Patients with at least one hospital admission } \\
\text { until } 2 \text { years }\end{array}$ & 2 & 391 & Risk Ratio (M-H, Random, 95\% Cl) & $0.44[0.08,2.36]$ \\
\hline
\end{tabular}

Analysis 2.1. Comparison 2 Interferon versus placebo: secondary outcomes, Outcome 1 Patients who required steroid treatment until first year.

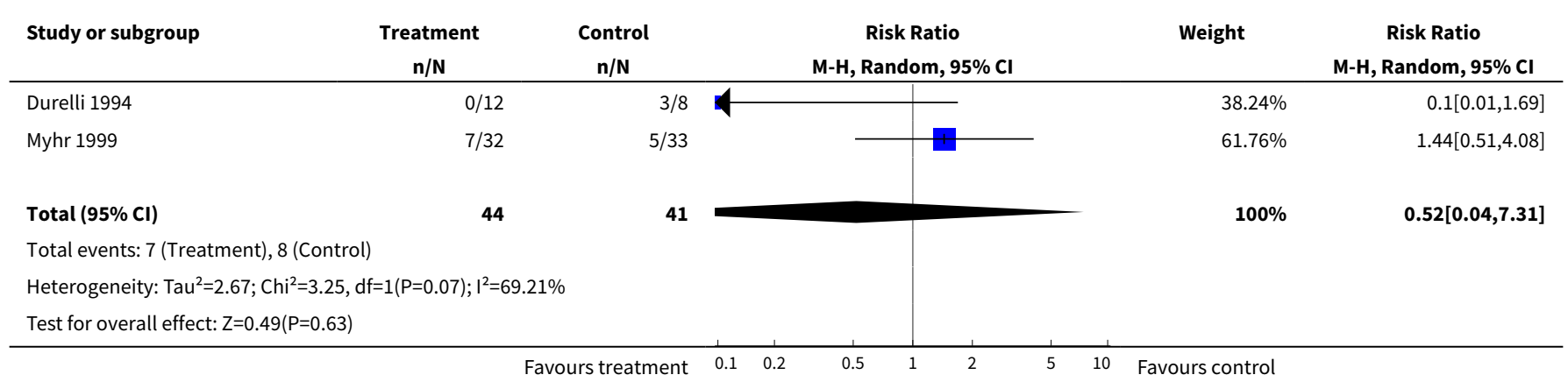

Analysis 2.2. Comparison 2 Interferon versus placebo: secondary outcomes, Outcome 2 Patients who required steroid treatment until 2 years.

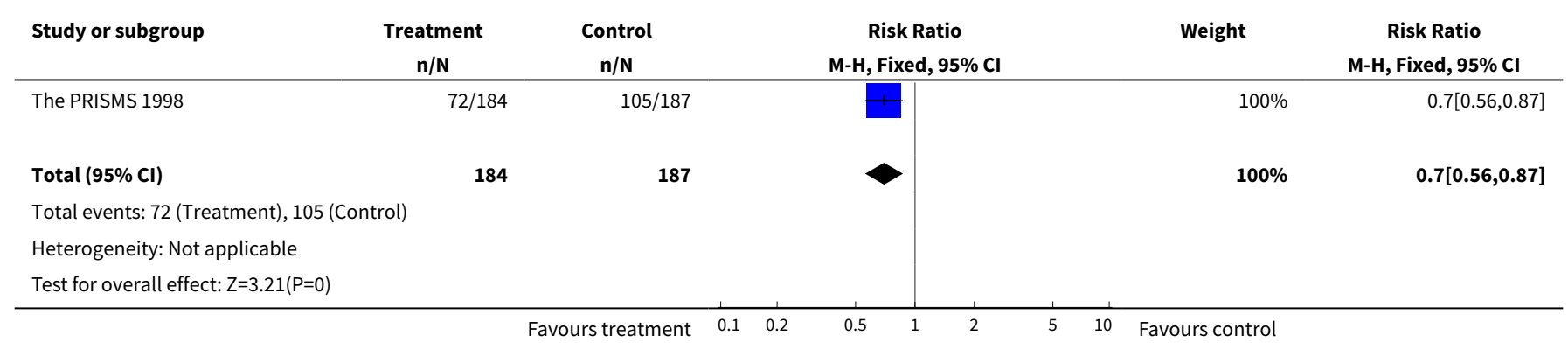

Analysis 2.3. Comparison 2 Interferon versus placebo: secondary outcomes, Outcome 3 Patients with at least one hospital admission until 2 years.

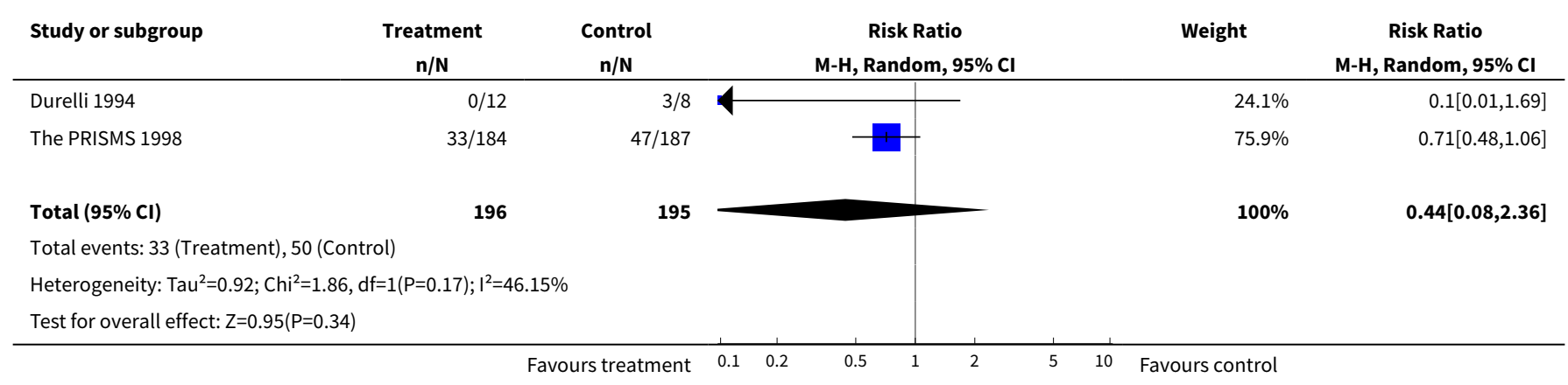


Comparison 3. interferon versus placebo: adverse events

\begin{tabular}{|c|c|c|c|c|}
\hline Outcome or subgroup title & $\begin{array}{l}\text { No. of } \\
\text { studies }\end{array}$ & $\begin{array}{l}\text { No. of } \\
\text { partici- } \\
\text { pants }\end{array}$ & Statistical method & Effect size \\
\hline $\begin{array}{l}1 \text { Patients who had clinical adverse events } \\
\text { during treatment }\end{array}$ & 6 & & $\begin{array}{l}\text { Risk Ratio (M-H, Random, } \\
95 \% \mathrm{Cl})\end{array}$ & Subtotals only \\
\hline 1.1 Flu-like symptoms & 4 & 1117 & $\begin{array}{l}\text { Risk Ratio (M-H, Random, } \\
95 \% \mathrm{Cl})\end{array}$ & $1.70[1.23,2.37]$ \\
\hline 1.2 Fever & 6 & 1199 & $\begin{array}{l}\text { Risk Ratio (M-H, Random, } \\
95 \% \mathrm{Cl})\end{array}$ & $1.92[1.52,2.43]$ \\
\hline 1.3 Myalgias/arthralgias & 6 & 1199 & $\begin{array}{l}\text { Risk Ratio (M-H, Random, } \\
95 \% \mathrm{Cl})\end{array}$ & $1.90[1.50,2.42]$ \\
\hline 1.4 Fatigue & 5 & 952 & $\begin{array}{l}\text { Risk Ratio (M-H, Random, } \\
95 \% \mathrm{Cl} \text { ) }\end{array}$ & $1.37[1.01,1.88]$ \\
\hline 1.5 Nausea and vomiting & 2 & 363 & $\begin{array}{l}\text { Risk Ratio (M-H, Random, } \\
95 \% \mathrm{Cl})\end{array}$ & $2.00[0.75,5.31]$ \\
\hline 1.6 Headache & 5 & 952 & $\begin{array}{l}\text { Risk Ratio (M-H, Random, } \\
95 \% \mathrm{Cl})\end{array}$ & $1.17[1.03,1.33]$ \\
\hline $\begin{array}{l}1.7 \text { Injection site-reactions by subcutaneous } \\
\text { route }\end{array}$ & 4 & 878 & $\begin{array}{l}\text { Risk Ratio (M-H, Random, } \\
95 \% \mathrm{Cl})\end{array}$ & $5.57[2.33,13.29]$ \\
\hline 1.8 Hair loss & 2 & 82 & $\begin{array}{l}\text { Risk Ratio (M-H, Random, } \\
95 \% \mathrm{Cl})\end{array}$ & $9.32[1.84,47.23]$ \\
\hline 1.9 Major psichic disorders & 6 & 1199 & $\begin{array}{l}\text { Risk Ratio (M-H, Random, } \\
95 \% \mathrm{Cl})\end{array}$ & $0.96[0.75,1.24]$ \\
\hline 1.10 Committed or attempted suicide & 3 & 919 & $\begin{array}{l}\text { Risk Ratio (M-H, Random, } \\
95 \% \mathrm{Cl})\end{array}$ & $1.98[0.41,9.56]$ \\
\hline $\begin{array}{l}2 \text { Patients who had abnormal laboratory val- } \\
\text { ues during treatment }\end{array}$ & 5 & & $\begin{array}{l}\text { Risk Ratio (M-H, Fixed, 95\% } \\
\text { Cl) }\end{array}$ & Subtotals only \\
\hline 2.1 Decreased hemoglobin values & 3 & 383 & $\begin{array}{l}\text { Risk Ratio (M-H, Fixed, 95\% } \\
\text { Cl) }\end{array}$ & $2.84[0.69,11.59]$ \\
\hline 2.2 Leukopenia & 5 & 1004 & $\begin{array}{l}\text { Risk Ratio (M-H, Fixed, 95\% } \\
\text { Cl) }\end{array}$ & $6.47[2.43,17.20]$ \\
\hline 2.3 Lymphopenia & 2 & 618 & $\begin{array}{l}\text { Risk Ratio (M-H, Fixed, 95\% } \\
\mathrm{Cl})\end{array}$ & $1.90[1.39,2.60]$ \\
\hline 2.4 Thrombocytopenia & 3 & 383 & $\begin{array}{l}\text { Risk Ratio (M-H, Fixed, 95\% } \\
\mathrm{Cl})\end{array}$ & $7.47[0.98,57.15]$ \\
\hline 2.5 Increased aspartate aminotransferase & 3 & 919 & $\begin{array}{l}\text { Risk Ratio (M-H, Fixed, 95\% } \\
\text { Cl) }\end{array}$ & $2.83[1.14,7.06]$ \\
\hline
\end{tabular}




\begin{tabular}{lllll}
\hline Outcome or subgroup title & $\begin{array}{l}\text { No. of } \\
\text { studies }\end{array}$ & $\begin{array}{l}\text { No. of } \\
\text { partici- } \\
\text { pants }\end{array}$ & Statistical method & Effect size \\
\hline 2.6 Increased alanine aminotransferase & 4 & 981 & $\begin{array}{l}\text { Risk Ratio (M-H, Fixed, 95\% } \\
\text { Cl) }\end{array}$ & $3.57[1.98,6.43]$ \\
\hline
\end{tabular}

Analysis 3.1. Comparison 3 interferon versus placebo: adverse events, Outcome 1 Patients who had clinical adverse events during treatment.

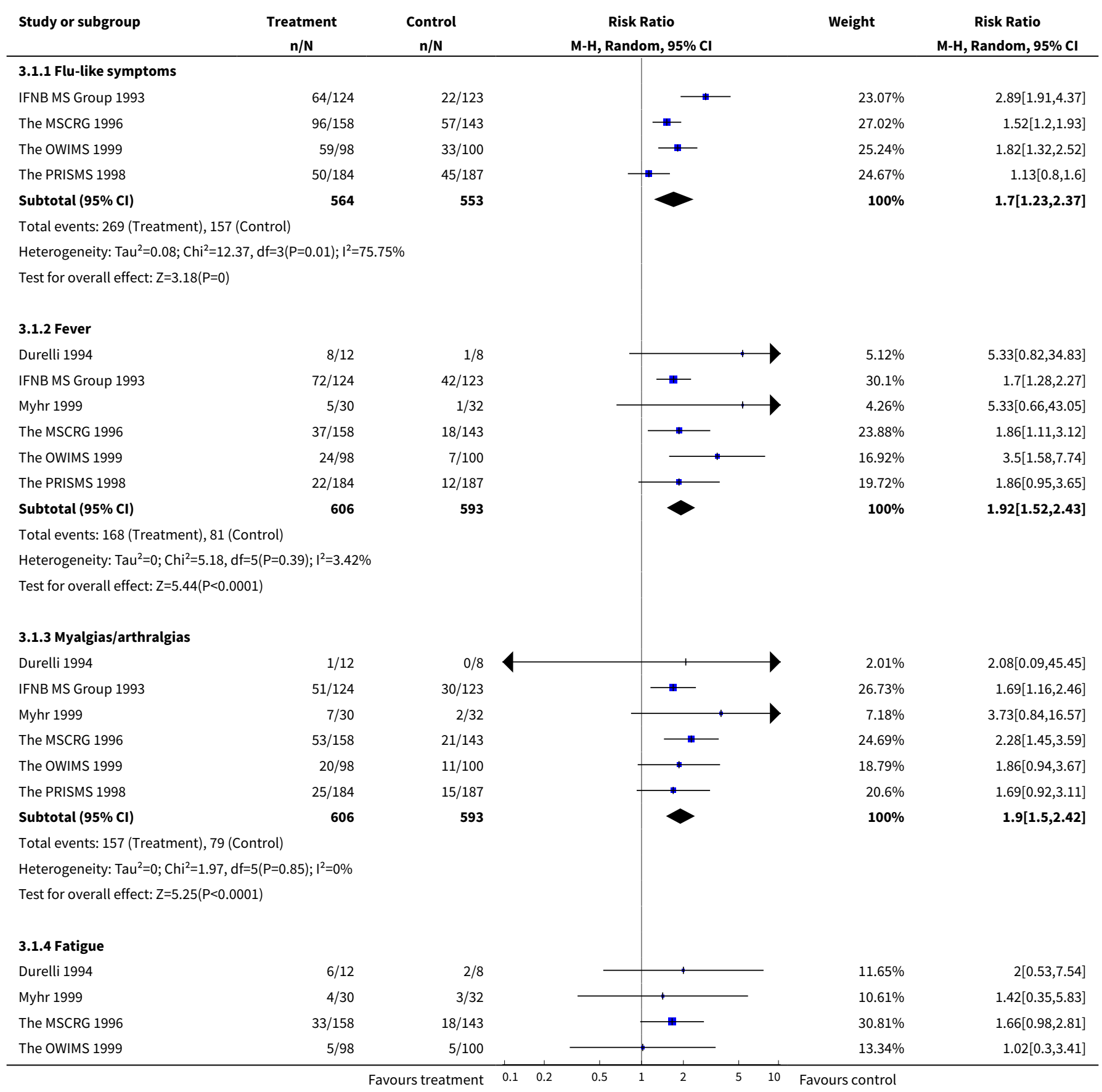




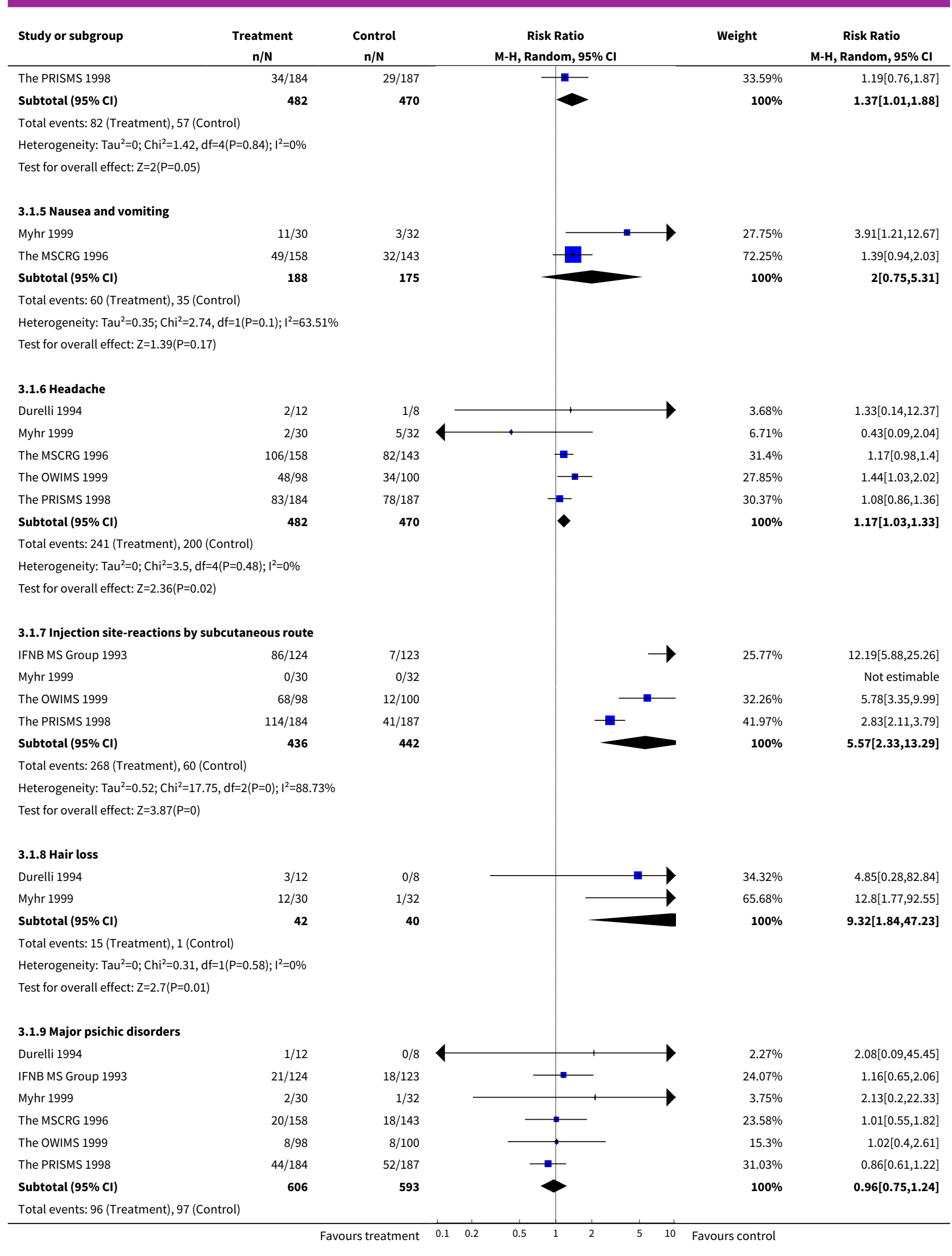




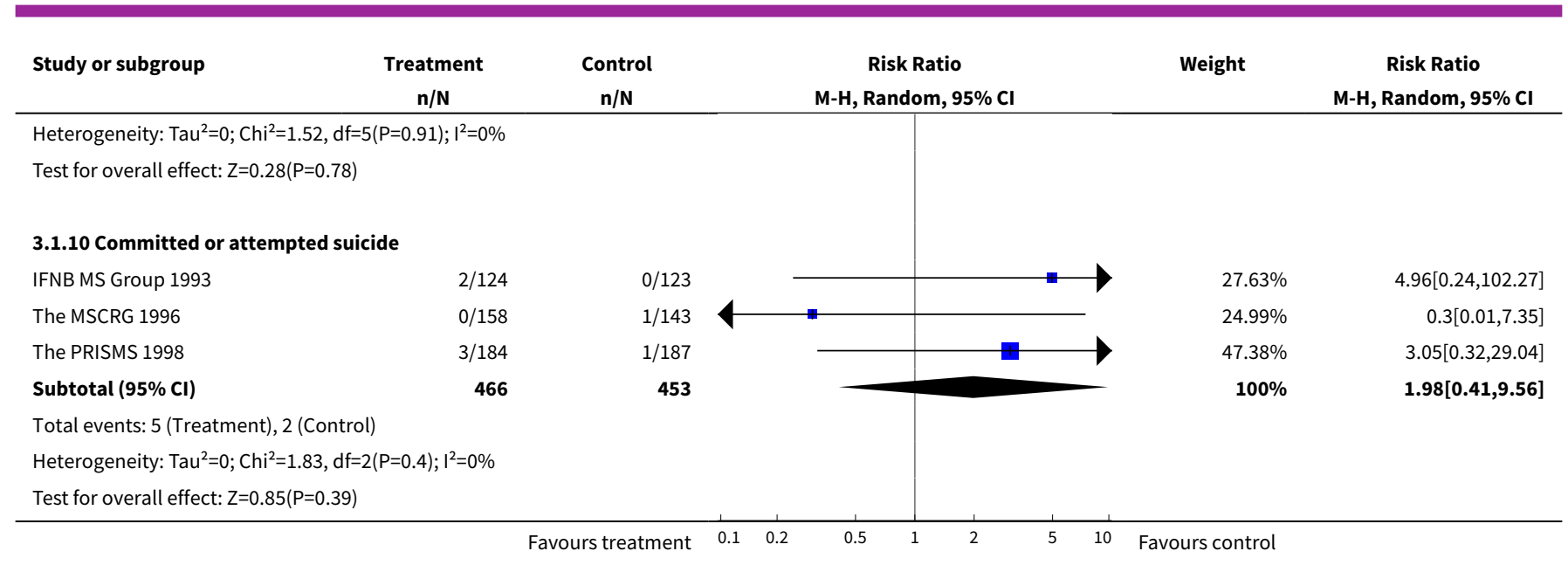

Analysis 3.2. Comparison 3 interferon versus placebo: adverse events, Outcome 2 Patients who had abnormal laboratory values during treatment.

\begin{tabular}{|c|c|c|c|c|c|}
\hline Study or subgroup & \multirow[t]{2}{*}{$\begin{array}{l}\text { Case } \\
\mathrm{n} / \mathrm{N}\end{array}$} & \multirow[t]{2}{*}{$\begin{array}{c}\text { Control } \\
\mathrm{n} / \mathrm{N}\end{array}$} & $\begin{array}{c}\text { Risk Ratio } \\
\text { M-H, Fixed, } 95 \% \mathrm{Cl} \\
\end{array}$ & \multirow[t]{2}{*}{ Weight } & \multirow[t]{2}{*}{$\begin{array}{c}\text { Risk Ratio } \\
\text { M-H, Fixed, } 95 \% \mathrm{Cl} \\
\end{array}$} \\
\hline \multicolumn{2}{|c|}{ 3.2.1 Decreased hemoglobin values } & & & & \\
\hline Durelli 1994 & $0 / 12$ & $0 / 8$ & & & Not estimable \\
\hline Myhr 1999 & $2 / 30$ & $0 / 32$ & & $18.74 \%$ & $5.32[0.27,106.54]$ \\
\hline The MSCRG 1996 & $5 / 158$ & $2 / 143$ & & $81.26 \%$ & $2.26[0.45,11.48]$ \\
\hline Subtotal $(95 \% \mathrm{CI})$ & 200 & 183 & & $100 \%$ & $2.84[0.69,11.59]$ \\
\hline \multicolumn{6}{|c|}{ Total events: 7 (Case), 2 (Control) } \\
\hline \multicolumn{6}{|c|}{ Heterogeneity: $\operatorname{Tau}^{2}=0 ; \mathrm{Chi}^{2}=0.24, \mathrm{df}=1(\mathrm{P}=0.62) ; \mathrm{I}^{2}=0 \%$} \\
\hline \multicolumn{6}{|c|}{ Test for overall effect: $Z=1.45(P=0.15)$} \\
\hline \multicolumn{6}{|l|}{ 3.2.2 Leukopenia } \\
\hline Durelli 1994 & $6 / 12$ & $0 / 8$ & & $12.96 \%$ & $9[0.58,140.5]$ \\
\hline IFNB MS Group 1993 & $4 / 124$ & $0 / 123$ & & $11.01 \%$ & $8.93[0.49,164.08]$ \\
\hline The MSCRG 1996 & $0 / 158$ & $0 / 143$ & & & Not estimable \\
\hline The PRISMS 1998 & $15 / 184$ & $3 / 187$ & & $65.24 \%$ & $5.08[1.5,17.26]$ \\
\hline Subtotal $(95 \% \mathrm{Cl})$ & 510 & 494 & & $100 \%$ & $6.47[2.43,17.2]$ \\
\hline \multicolumn{6}{|c|}{ Total events: 29 (Case), 3 (Control) } \\
\hline \multicolumn{6}{|c|}{ Heterogeneity: $\operatorname{Tau}^{2}=0 ; \mathrm{Chi}^{2}=0.31, \mathrm{df}=3(\mathrm{P}=0.96) ; \mathrm{I}^{2}=0 \%$} \\
\hline \multicolumn{6}{|c|}{ Test for overall effect: $Z=3.74(P=0)$} \\
\hline \multicolumn{6}{|l|}{ 3.2.3 Lymphopenia } \\
\hline IFNB MS Group 1993 & $58 / 124$ & $36 / 123$ & & $83.89 \%$ & $1.6[1.15,2.23]$ \\
\hline The PRISMS 1998 & $24 / 184$ & $7 / 187$ & & $16.11 \%$ & $3.48[1.54,7.89]$ \\
\hline Subtotal $(95 \% \mathrm{CI})$ & 308 & 310 & & $100 \%$ & $1.9[1.39,2.6]$ \\
\hline \multicolumn{6}{|c|}{ Total events: 82 (Case), 43 (Control) } \\
\hline \multicolumn{6}{|c|}{ Heterogeneity: $\mathrm{Tau}^{2}=0 ; \mathrm{Chi}^{2}=3.16, \mathrm{df}=1(\mathrm{P}=0.08) ; \mathrm{I}^{2}=68.37 \%$} \\
\hline \multicolumn{6}{|c|}{ 3.2.4 Thrombocytopenia } \\
\hline Durelli 1994 & $0 / 12$ & $0 / 8$ & & & Not estimable \\
\hline Myhr 1999 & $7 / 30$ & $1 / 32$ & & $100 \%$ & $7.47[0.98,57.15]$ \\
\hline & & s treatment 0.2 & 0.5 & control & \\
\hline
\end{tabular}




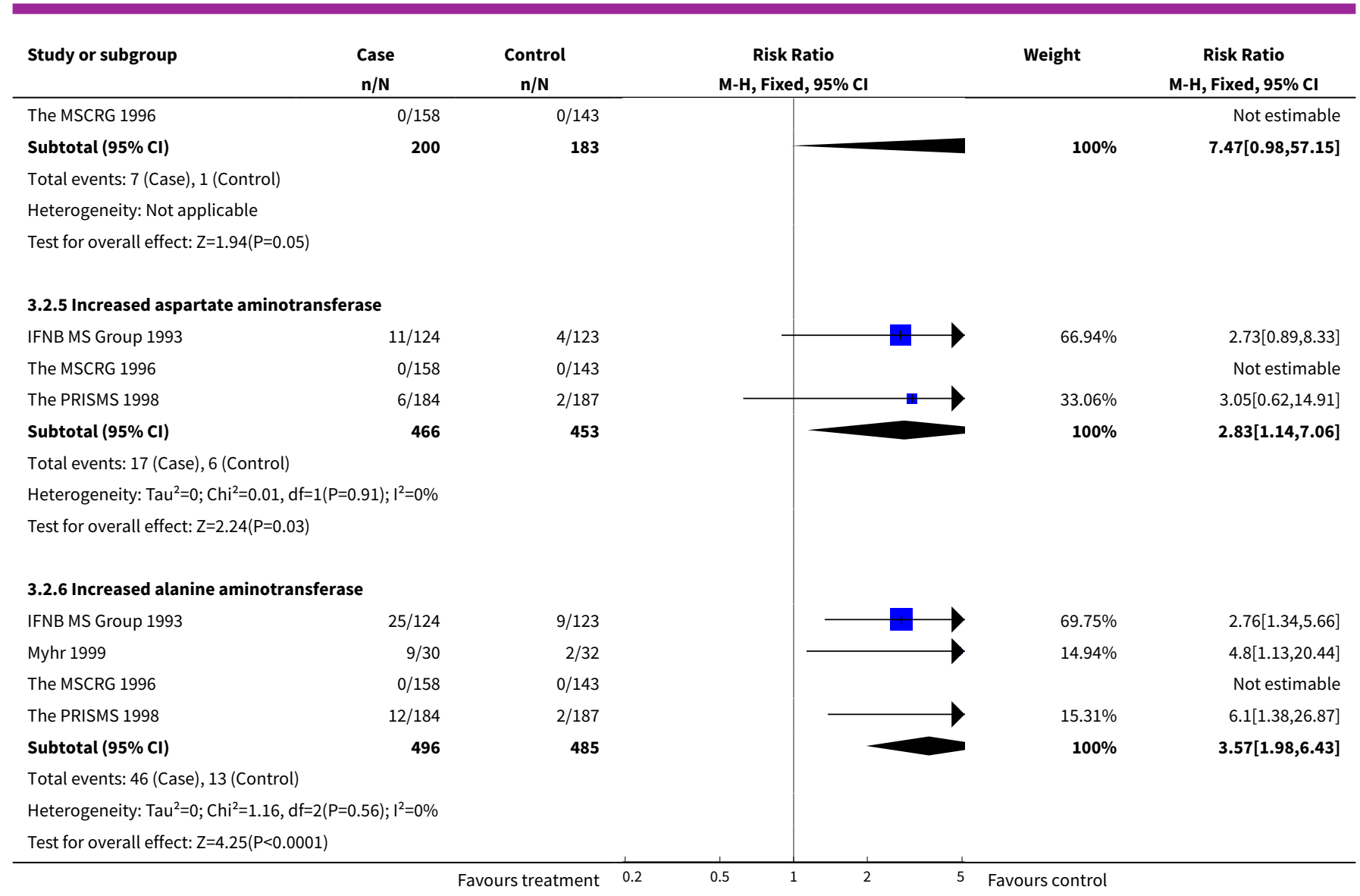

\section{ADDITIONAL TABLES}

Table 1. Kurtzke Expanded Disability Status Scale (EDSS)

\section{Score}

0-Normal neurologic examination

1.0-No disability, minimal signs on one Functional System (FS)*

1.5-No disability, minimal signs on $>1$ FS

2.0-Minimal disability in $1 \mathrm{FS}$

2.5-Minimal disability in 2 FS

3.0-Moderate disability in $1 \mathrm{FS}$; or mild disability in 3-4 FS, though fully ambulatory

3.5-Fully ambulatory but with moderate disability in 3-4 FS

4.0-Fully ambulatory without aid, up and about $12 \mathrm{hrs}$./day despite relatively severe disability. Able to walk without aid 500meters

4.5-Fully ambulatory without aid, up and about much of day, able to work a full day, may otherwise have some limitations of full activity or require minimal assistance. Relatively severe disability. Able to walk without aid 300meters 
Table 1. Kurtzke Expanded Disability Status Scale (EDSS) (Continued)

5.0-Ambulatory without aid for about $200 \mathrm{~m}$. Disability impairs full daily activities

5.5-Ambulatory for $100 \mathrm{~m}$, disability precludes full daily activities

6.0-Intermittent or unilateral constant assistance required to walk $100 \mathrm{~m}$ with or without resting

6.5-Constant bilateral support required to walk $20 \mathrm{~m}$. without resting

7.0-Unable to walk beyond $5 \mathrm{~m}$ even with aid, essentially restricted to wheelchair, wheels self, transfers alone

7.5-Unable to take more than a few steps, restricted to wheelchair, any need aid in transfer, wheels self but may require motorized chair for full day's activities

8.0-Essentially restricted to bed or chair or perambulated in wheelchair, but may be out of bed much of day, retains self care functions, generally effective use of arms

8.5-Essentially restricted to bed much of day,some effective use of arms, some self care functions

8.5-Essentially restricted to bed much of day,some effective use of arms, some self care functions

9.0-Helpless bed patient, can communicate and eat

9.5-Unable to communicate effectively or eat/swallow

10.0-Death

* Functional Systems are eight scales representing different functions of the Central Nervous System (Kurtzke 1961). Each system is rated on a five-point (three systems) or six-point (four systems) response scale except 'Other Functions' which is rated dichotomously ( 0 = none, 1 = any other neurological findings attributed to multiple sclerosis)

Table 2. Withdrawals and losses to follow-up in the included studies

\begin{tabular}{|c|c|c|c|c|}
\hline Study & Withdrawals & Losses to follow-up & Total & $\begin{array}{l}\% \text { of pa- } \\
\text { tients }\end{array}$ \\
\hline MSCRG (1996) & $\begin{array}{l}23 \text { (included in analy- } \\
\text { sis) }\end{array}$ & $\begin{array}{l}129 \text { (premature study termina- } \\
\text { tion) }\end{array}$ & 129 & 43 \\
\hline Myhr (1999) & 3 & 3 & 6 & 9 \\
\hline Durelli (1994) & 0 & 0 & 0 & 0 \\
\hline Knobler (1993) & 1 & 4 & 5 & 38 \\
\hline OWIMS (1999) & 8 & 8 & 16 & 8 \\
\hline PRISMS (1998) & 20 & 16 & 36 & 10 \\
\hline IFNB MS Group (1993) & unreported & unreported & 48 & 19 \\
\hline Polman (2003) & 2 & 4 & 6 & 7 \\
\hline
\end{tabular}


Table 3. Side effects or adverse events: definitions as reported in the original articles
Study
Data in the articles

IFNB MS Study Group (1993)

Abnormal laboratory values: 1 ) Increased aspartate aminotransferase (AST) = above upper limit of normal; 2) Increased alanine aminotransferase (ALT) = above upper limit of normal; 3) Leukopenia = white blood cells $<2,999$ per mm3; 4) Lymphopenia = lymphocytes $<1,499$ per mm3; 5) Decreased haemoglobin values $=$ no definition; 6 ) Thrombocytopenia $=$ no definition. Clinical side effects $=$ no definition. Neutralizing antibodies against interferon $(\mathrm{NAB})=$ neutralizing titres were expressed relative to the National Institute of Health $(\mathrm{NIH})$ standard, with the limit of detection at 20 neutralizing units per milliliter

Knobler (1993)

Abnormal laboratory values: 1 ) Increased AST = no definition; 2 ) Increased ALT = no definition; 3 ) Leukopenia $=$ no definition; 4) Lymphopenia $=$ lymphocytes $<1,000$ per $\mathrm{mm} 3$; 5) Decreased haemoglobin values = no definition; 6 ) Thrombocytopenia = no definition. Clinical side effects = no definition. $\mathrm{NAB}=$ neutralizing titres were expressed relative to the NIH standard, with the limit of detection at 20 neutralizing units per milliliter

Durelli (1994)

Abnormal laboratory values: 1 ) Increased AST = mild elevation: $2 \times$ normal value and moderate elevation: $3 \times$ normal value; 2 ) Increased AST and ALT = mild elevation: $2 \times$ normal value and moderate elevation: 3 x normal value; 3) Neutropenia = cell number between 1,000 and 2,000 per mm3;4) Lymphopenia = no definition; 5) Decreased haemoglobin values = no definition; 6) Thrombocytopenia $=$ no definition. Depression = tested with the Hamilton Depression Scale; Flu-like syndrome = contemporary presence of fever, headache, arthralgias and myalgias; Other clinical outcomes = no definition. $N A B=$ neutralizing titres were not defined

The MSCRG (1995)

Abnormal laboratory values: 1) Increased AST; 2) Increased ALT; 3) Leukopenia; 4) Lymphopenia; 5) Decreased haemoglobin values; 6) Thrombocytopenia. The Authors reported "Adverse events and current laboratory data were monitored and recorded according to the Food and Drug Administration (FDA) phase III requirements". Moreover, they reported "FDA, HHS 21 CFR, Chapt. 1, 312.32, part c, 4/1/90". Depression = tested with the Beck Depression Inventory and Functional Assessment: using several scales = The MS Functional Disability Assessment, The Functional Indipendence Measure, The Barthel Index, The Incapacity Status Scale, and The Brief Symptom Inventory. $\mathrm{NAB}=$ neutralizing titres were expressed relative to the NIH standard, with the limit of detection at 20 neutralizing units per milliliter

The PRISMS (1998)

Abnormal laboratory values: 1 ) Increased AST = no definition; 2 ) Increased ALT = no definition; 3 ) Leukopenia $=$ no definition; 4) Lymphopenia $=$ lymphocytes $<1,000$ per mm3; 5) Decreased haemoglobin values = no definition; 6 ) Thrombocytopenia $=$ no definition. Depression $=$ tested with the Beck Depression Inventory, The Centre for Epidemiologic Studies' Depression Mood Scale, and the General Health Questionnaire. Other clinical outcomes $=$ no definition. NAB = neutralizing titres were expressed relative to the NIH standard, with the limit of detection at 20 neutralizing units per milliliter. The Authors used the four grades of the World Health Organization about toxic effects

Myhr (1999)

Abnormal laboratory values: 1) Increased AST = no definition; 2 ) Increased ALT = no definition; 3 ) Leukopenia = no definition; 4) Lymphopenia = no definition; 5) Decreased haemoglobin values $=$ no definition; 6) Thrombocytopenia = no definition. Clinical side effects = no definition. $\mathrm{NAB}=$ the Authors reported that "they were analyzed by F. Hoffmann-La Roche according to standardized protocols"

The OWIMS (1999)

Abnormal laboratory values: 1 ) Increased AST = no definition; 2 ) Increased ALT = no definition; 3 ) Leukopenia = no definition; 4) Lymphopenia = no definition; 5) Decreased haemoglobin values $=$ no definition; 6) Thrombocytopenia $=$ no definition. Clinical side effects = no definition. NAB: no definition 
Table 4. Magnetic Resonance Imaging (MRI) as reported in the original articles

\begin{tabular}{|c|c|c|c|c|}
\hline Study & MRI & $\begin{array}{l}\text { Year(s) of } \\
\text { follow-up }\end{array}$ & Control group & Treated group \\
\hline $\begin{array}{l}\text { IFNB } \\
(1993)\end{array}$ & $\begin{array}{l}\text { Mean [standard error (SE)] and } \\
\text { median annual \% change of } \\
\text { total lesion area. }\end{array}$ & $\begin{array}{l}1 \text { and } \\
2 \text { years } \\
\text { from ran- } \\
\text { domisa- } \\
\text { tion }\end{array}$ & $\begin{array}{l}\text { At 1st year: mean } 110.6 \text {; median } 6.7 \text { (SE } \\
\text { 96.3). At 2nd year: mean } 43.8 ; \text { median } \\
11.9 \text { (SE 14.0). N. of patients } 72\end{array}$ & $\begin{array}{l}\text { At 1st year: mean } 5.4 \text {; me- } \\
\text { dian }-4.9 \text { (5.1). Number of } \\
\text { patients } 77 \text {. At } 2 \text { nd year: } \\
\text { mean 9.4; median - } 5.6 \text { (SE } \\
\text { 8.5). Number of patients } \\
73\end{array}$ \\
\hline
\end{tabular}

Knobler No MRI outcome

(1993)

\begin{tabular}{ll}
\hline Durelli & Number of patients who had \\
(1994) & active lesions. Total number of \\
enlarging lesions and new le- \\
sions in the two groups. Mean \\
(SE)number of active lesions \\
per patient
\end{tabular}

6 months Number of patients with active scans: 6 of from ran- 8 patients (enlarging lesions: 12 of 6 ; new domisa- lesions: 15 of 6 ). Mean number of active tion. lesions per patient 3.37 (1.03)
Number with active scans: 1 of 12 patients (enlarging lesions: 1; new lesions: $0)$. Mean number of active lesions per patient 0.08 (0.08)

\begin{tabular}{|c|c|c|c|}
\hline $\begin{array}{l}\text { MSCRG } \\
\text { (1995) }\end{array}$ & $\begin{array}{l}\text { Number of patients who had } \\
\text { active lesions. Mean (SE) num- } \\
\text { ber and volume of active le- } \\
\text { sions per patient. Median \% } \\
\text { change of total lesion volume } \\
\text { (mm3). }\end{array}$ & $\begin{array}{l}1 \text { and } \\
2 \text { years } \\
\text { from ran- } \\
\text { domisa- } \\
\text { tion }\end{array}$ & $\begin{array}{l}\text { At 1st year: number of patients with ac- } \\
\text { tive scans: } 52 \text { of } 123 \text { patients. Mean num } \\
\text { ber of active lesions per patient } 1.59 \\
(0.31) \text {. Mean volume per patient } 96.5 \\
\text { (21.2) mm3. Median change }-3.3 \% \text {. At } \\
\text { 2nd year: number of patients with active } \\
\text { scans: } 35 \text { of } 82 \text { patients. Mean number } \\
\text { of active lesions per patient } 1.65(0.48) \text {. } \\
\text { Mean volume per patient } 122.4(48.5) \\
\text { mm3. Median change }-6.5 \% \text {. }\end{array}$ \\
\hline
\end{tabular}

At 1st year: number of patients with active scans: 40 of 134 patients. Mean number of active lesions per patient 1.04 (0.28). Mean volume per patient 70.0 (24.9) $\mathrm{mm} 3$. Median change $-13.1 \%$. At 2 nd year: number of patients with active scans: 24 of 83 patients. Mean number of active lesions per patient $0.80(0.22)$. Mean volume per patient 74.1 (38.3) mm3. Median change $-13.2 \%$.

\begin{tabular}{|c|c|c|c|}
\hline $\begin{array}{l}\text { PRISMS } \\
(1998)\end{array}$ & $\begin{array}{l}\text { Median } \% \text { change of total le- } \\
\text { sion burden (area or volume?). } \\
\text { Difference (\%) of the num- } \\
\text { ber of active lesions between } \\
\text { treated and control groups. }\end{array}$ & $\begin{array}{l}2 \text { years } \\
\text { from ran- } \\
\text { domisa- } \\
\text { tion }\end{array}$ & Median 10.9 (N. 187 patients). \\
\hline $\begin{array}{l}\text { Myhr } \\
\text { (1999) }\end{array}$ & $\begin{array}{l}\text { Mean (no SE) and median of } \\
\text { new active lesions per patient. } \\
\text { Number of patients with new } \\
\text { active lesions. Mean (no SE) } \\
\text { and median of total number } \\
\text { of lesions per patient (number } \\
\text { of T1-weighted active lesions }\end{array}$ & $\begin{array}{l}6 \text { months } \\
\text { and } 1 \text { year } \\
\text { from ran- } \\
\text { domisa- } \\
\text { tion }\end{array}$ & $\begin{array}{l}\text { At } 6 \text { th month: mean } 7.3 \text { and median } 2.5 \\
\text { new active lesions per patient ; } 24 \text { of } 32 \\
\text { patients with new active lesions; mean } \\
1.6 \text { and median } 1.0 \text { total number of le- } \\
\text { sions per patient. At } 1 \text { st year: mean } 1.6 \\
\text { and median } 0.0 \text { total number of lesions } \\
\text { per patient. (N. } 32 \text { patients) }\end{array}$ \\
\hline
\end{tabular}

Median -3.8 (N. 184). Difference of active lesions $78 \%$ than placebo group sions)

At 6th month: mean 1.4 and median 0.0 new active lesions per patient; 9 of 28 patients with new active lesions; mean 0.3 and median 0.0 total number of lesions per patient. At 1st year: mean 0.7 and median 0.0 total number of lesions per patient (N. 28 patients)
At 24th week: mean and median number of combined unique active lesions $0.8(1.1)$ and 0.3 per 
Table 4. Magnetic Resonance Imaging (MRI) as reported in the original articles (Continued) proportion of scans showing active lesions. Mean (no SE) domisasions 0.3 per patient; median number of and median $\%$ change of total lesion area. tion T1-Gadolinium unique active lesions 0.7 per patient; $50 \%$ of scans with combined active lesions. At 48th week: mean $15.5 \%$ and median $5.9 \%$ change of total lesion area (N. of patients at 24th and 48th week = unknown). patient; median number of proton density/T2 unique active lesions 0.2 per patient; median number of T1-Gadolinium unique active lesions 0.3 per patient; $33 \%$ of scans with combined active lesions. At 48th week: mean $0.8 \%$ and median $-1.4 \%$ change of total lesion area (N. of patients at 24th and 48th week = unknown).

Median and quartiles (Q1;

6 months Median and quartiles (Q1; Q3): 4.0 (2.7; from ran- 10.0) Q3): $9.0(1.0 ; 16.0)$
Polman Cumulative number of newly (2003) active lesions over 6 months. 


\begin{tabular}{|c|c|c|c|c|c|c|c|c|c|}
\hline Outcomes & 0.1 & 0.2 & 0.3 & 0.4 & 0.5 & 0.6 & 0.7 & 0.8 & 0.9 \\
\hline $\begin{array}{l}\text { Patients who continued to experience exacerbations during } \\
\text { the first year }\end{array}$ & $\begin{array}{l}37 \\
(22: 333)\end{array}$ & $\begin{array}{l}19 \\
(11: 177)\end{array}$ & $\begin{array}{l}12 \\
(7: 111)\end{array}$ & $9(6: 83)$ & $7(4: 67)$ & $6(4: 56)$ & $5(3: 48)$ & $5(3: 42)$ & $4(2: 37)$ \\
\hline $\begin{array}{l}\text { Patients who continued to experience exacerbations during } \\
\text { the first } 2 \text { years }\end{array}$ & $\begin{array}{l}50 \\
(37: 83)\end{array}$ & $\begin{array}{l}25 \\
(19: 42)\end{array}$ & $\begin{array}{l}17 \\
(12: 28)\end{array}$ & $13(9: 21)$ & $10(7: 17)$ & $8(6: 14)$ & $7(5: 12)$ & $6(5: 10)$ & $6(4: 9)$ \\
\hline $\begin{array}{l}\text { Patients who continued to experience exacerbations during } \\
\text { the first } 2 \text { yrs (base case) } \\
\text { Patients who continued to experience exacerbations during } \\
\text { the first } 2 \text { yrs (base case) }\end{array}$ & & & & & & & & & \\
\hline Patients who progressed during the first 2 years & $\begin{array}{l}32 \\
(22: 77)\end{array}$ & $\begin{array}{l}16 \\
(11: 38)\end{array}$ & $11(7: 26)$ & $8(6: 19)$ & $6(4: 15)$ & $5(4: 13)$ & $5(3: 11)$ & $4(3: 10)$ & $4(2: 9)$ \\
\hline
\end{tabular}




\section{AP PE N D I C E S}

\section{Appendix 1. MEDLINE (PubMed) search strategy}

(((("Multiple Sclerosis"[mh]) OR ("Myelitis, Transverse"[mh:noexp]) OR ("Demyelinating Diseases"[mh:noexp]) OR ("Encephalomyelitis, Acute Disseminated"[mh:noexp]) OR ("Optic Neuritis"[mh])) OR ((("multiple sclerosis") OR ("neuromyelitis optica") OR ("transverse myelitis") OR (encephalomyelitis) OR (devic) OR ("optic neuritis")) OR ("demyelinating disease*") OR ("acute disseminated encephalomyelitis"))) AND (((randomized controlled trial[pt]) OR (controlled clinical trial[pt]) OR (randomized[tiab]) OR (placebo[tiab]) OR (drug therapy[sh]) OR (randomly[tiab]) OR (trial[tiab]) OR (groups[tiab])) NOT ((animals[mh]) NOT ((animals[mh]) AND (human[mh]))))) AND (("Interferon-beta"[Mesh]) OR (rebif OR "interferon beta" OR "beta interferon" OR betaseron OR avonex))

\section{Appendix 2. EMBASE (EMBASE.com) search strategy}

((('encephalomyelitis'/exp) OR ('demyelinating disease'/exp) OR ('multiple sclerosis'/exp) OR ('myelooptic neuropathy'/exp) OR ('multiple sclerosis':ti,ab) OR ('neuromyelitis optica':ab,ti) OR (encephalomyelitis:ab,ti) OR (devic:ti,ab)) AND (('crossover procedure'/ exp) OR ('double blind procedure'/exp) OR ('single blind procedure'/exp) OR ('randomized controlled trial'/exp) OR (random*:ab,ti) OR (factorial*:ab,ti) OR (crossover:ab,ti) OR (cross:ab,ti AND over:ab,ti) OR (placebo:ab,ti) OR ('double blind':ab,ti) OR ('single blind':ab,ti) OR (assign*:ab,ti) OR (allocat*:ab,ti) OR (volunteer*:ab,ti)))) AND (('beta interferon'/exp) OR ('interferon'/de) OR ('interferon beta':ab,ti AND rebif:ab,ti) OR (betaseron:ab,ti) OR ('beta interferon') OR (avonex:ab,ti)) AND [humans]/lim AND [embase]/lim

\section{WHAT'S NEW}

\begin{tabular}{lll}
\hline Date & Event & Description \\
\hline 11 April 2008 & Amended & Converted to new review format. \\
\hline
\end{tabular}

\section{H I S T O R Y}

Protocol first published: Issue 1, 2000

Review first published: Issue 4, 2001

\begin{tabular}{lll}
\hline Date & Event & Description \\
\hline 29 July 2007 & Amended & No changes to conclusion, added a review author \\
\hline 29 April 2007 & New search has been performed & Run searches for new studies \\
\hline
\end{tabular}

\section{CONTRIBUTIONS OF AUTHORS}

Prof G PA Rice and Dr G Filippini conceived the idea and development of the project, posed the questions of the research project, designed the protocol, appraised the relevance and the validity of the papers and co-ordinated the review. G Rice abstracted data and wrote to sponsors of trials for additional information. They both analyzed the results and wrote the text of the review.

Dr B Incorvaia and Dr L Munari: They both were involved in the search strategy, abstracted data and helped in the analysis of the results and writing of the test of the review. Dr B Incorvaia organized retrieval of papers.

Prof Chris Polman: Assisted in the design of the protocol, abstracted data, assisted in data interpretation and reviewed the manuscript drafts.

Dr R D'Amico assisted in statistical analysis and writing of the test of the review.

Prof George Ebers: Assisted in the design of the protocol, data interpretation and reviewed the manuscript drafts.

Dr E Parmelli collaborated to the update of the review.

\section{DECLARATIONS OF INTEREST}

The review was assembled, analysed and reported independent from any pharmaceutical company input.

Prof Rice has participated in clinical trials sponsored by SCHERING, SERONO, BERLEX, BIOGEN, and TEVA. He has received honoraria from these companies. 
Prof Ebers has received honoraria for lectures found to be sponsored by relevant companies and has been an investigator for several clinical trials in multiple sclerosis including three interferon studies involving SCHERING, SERONO funding. He does not feel his opinions (which are largely critical of the efficacy of interferons) are influenced by these associations.

Prof Polman has received honoraria for lecturing, consultancy from companies producing interferon beta.

Dr Filippini has received travel expenses from Farmades pharmaceutical company for participating at neurological conferences. Drs Munari, D'Amico, Incorvaia and Parmelli have no conflict of interest.

\section{SOURCES OF SUPPORT}

\section{Internal sources}

- Department of Clinical Neurological Sciences, University of Western Ontario, Canada.

- National Neurological Institute C. Besta, Milan, Italy.

\section{External sources}

- Multiple Sclerosis Society of Canada (applied), Canada.

- Fondazione Italiana Sclerosi Multipla, Italy.

\section{N DEX TERMS}

\section{Medical Subject Headings (MeSH)}

Interferon Type I [ ${ }^{\star}$ therapeutic use]; Multiple Sclerosis, Relapsing-Remitting [ ${ }^{\star}$ drug therapy]; Randomized Controlled Trials as Topic; Recombinant Proteins

\section{MeSH check words}

Humans 